\title{
Evolução entre a educação florestal e educação em madeira: Definições, formações, cronologias e perspectivas
}

\author{
Evolution between forestry education and timber education: Definitions, formations, chronologies \\ and perspectives
}

Evolución entre educación forestal y educación en madera: Definiciones, formaciones, cronologías y perspectivas

\section{Resumo}

As primeiras escolas florestais foram criadas na Europa Ocidental em meados do Século XVIII. Ao final do Século XIX, a Educação Florestal foi estruturada para intervir nos ecossistemas florestais e garantir a gestão sustentável de seus recursos. Assim, a cadeia florestal avançou na busca por soluções de maior valor e qualidade, incluindo os produtos florestais nos currículos educacionais. No Século XX, a Educação em Madeira foi concebida para abordar a madeira e seu processamento. Então, este artigo teve como objetivo examinar, nos cenários global e brasileiro, a Educação Florestal e a Educação em Madeira para compreender suas características, cronologias e perspectivas. Extensivas consultas em websites de universidades e literaturas científicas foram conduzidas para assegurar a informação necessária para suportar as discussões. Os cursos de graduação em Educação Florestal e em Madeira têm sido intitulados por diferentes designações, onde as nomenclaturas generalistas são frequentes nas áreas de silvicultura e os nomes mais específicos são comuns nos campos da madeira. A Educação Florestal se iniciou na Europa e se espalhou pelo mundo durante dois séculos, surgindo no Brasil em meados do Século XX. A partir de modernas tecnologias industriais, a Educação em Madeira foi desenvolvida no Hemisfério Norte e se espalhou globalmente ao longo de um século até a sua inserção no Brasil ao final do Século XX. Um declínio estudantil tem sido observado globalmente nessas carreiras, razões pelas quais novos estímulos e políticas são requeridos por uma sociedade ávida pelos bioprodutos sustentáveis e genuinamente preocupada com as questões ambientais.

Palavras-chave: Biorrecursos; Silvicultura; Tecnologia da madeira; Ciência; Formação. 


\begin{abstract}
The first forestry schools were created in the Western Europe in the mid-eighteenth Century. In the late of 19th Century, Forest Education was structured to intervene in forestry ecosystems and ensure the sustainable management of their resources. Thus, forestry chain advanced in the quest for higher value and quality solutions. In the early of 20th Century, Timber Education was designed to approach the wood and its processing. Then, this paper aimed to examine, in the global and Brazilian scenarios, Forest Education and Timber Education to understand their features, chronologies and perspectives. Broad consultations in the websites of universities and scientific literature were carried out to ensure the necessary information to support discussions. Forest and Timber Education undergraduate courses have been titled by different designations, where generalist nomenclatures are frequent in the forestry areas and more specific names are common in the wood fields. The Forestry Education initiated in Europe and spread across the world over two centuries, arising in Brazil in the middle of the 20th Century. From modern industry technologies, the Timber Education was developed in the Northern Hemisphere, and it spread globally over a century until its insertion in Brazil at the end of the 20th Century. A student decline has been globally observed in these careers, reasons why new stimuli and policies are required by a society eager for sustainable bioproducts and genuinely concerned about environmental issues.
\end{abstract}

Keywords: Bioresources; Sylviculture; Wood technology; Science; Formation.

\title{
Resumen
}

Las primeras escuelas forestales se crearon en Europa occidental a mediados del siglo XVIII. A finales del siglo XIX, la Educación Forestal se estructuró para intervenir en los ecosistemas forestales y asegurar la gestión sostenible de sus recursos. Así, la cadena forestal ha avanzado en la búsqueda de soluciones de mayor valor y calidad, incluyendo los productos forestales en los planes de estudio académicos. En el siglo XX, la Educación en Madeira se concibió para abordar la madera y su procesamiento. Entonces, este artículo tuvo como objetivo examinar, en los escenarios global y brasileño, la Educación Forestal y la Educación en Madeira para comprender sus características, cronologías y perspectivas. Se llevaron a cabo amplias consultas en los sitios web de las universidades y en la literatura científica para garantizar la información necesaria para respaldar los debates. Los cursos de pregrado en Educación Forestal y en Madeira se han titulado con diferentes denominaciones, donde las nomenclaturas generalistas son frecuentes en las áreas de silvicultura y los nombres más específicos son comunes en los campos de la madera. La Educación Forestal comenzó en Europa y se extendió por el mundo durante dos siglos, surgiendo en Brasil a mediados del siglo XX. Basada en tecnologías industriales modernas, la Educación en Madeira se desarrolló en el Hemisferio Norte y se extendió globalmente durante un siglo hasta su inserción en Brasil a fines del siglo XX. Se ha observado un declive estudiantil a nivel global en estas carreras, razones por las cuales nuevos estímulos y políticas son requeridos por una sociedad ávida de los bioproductos sostenibles y genuinamente preocupada por los temas ambientales.

Palabras clave: Recursos biológicos; Silvicultura; Tecnología de la madera; Ciencia; Formación.

\section{Introdução}

O conhecimento na Educação Superior deve ser compartilhado e absorvido por comunidades distintas para que vantagens competitivas sejam geradas à sociedade (Acevedo-Correa, 2019). Por isso, esse avanço educacional estimula ao progresso das novas áreas de conhecimento teórico-prático.

A Educação Florestal emergiu inicialmente na Europa, a partir de cursos para a capacitação técnica de interessados nos ofícios desenvolvidos nas florestas (Poggiani, 1980). Entre 1760 e 1860, as escolas florestais foram pioneiras diferentes países como, por exemplo, Alemanha, Áustria, Espanha, França, Hungria, Itália, Rússia e, sobretudo, nos países escandinavos. De acordo com Paillé (2003), os cursos florestais foram inseridos na América do Norte durante os anos iniciais do Século XX, especificamente, a partir do processo de imigração europeia vivido nessa região. Atualmente, a formação florestal se espalhou por todo o mundo.

A Educação Florestal se desenvolveu a partir de um objetivo principal para fornecer praticantes capacitados e estudos livres para treinar as habilidades de subsistência e a capacidade de resolução de problemas em ambientes florestais (Duncan et al., 1989). Para isso, os silvicultores são treinados em ciências físicas e biológicas relativas ao ecossistema florestal e, sobretudo, em ciência, tecnologia e economia para as produções de floresta e madeira (Bachelard, 1994). A evolução dessas frentes impulsionou as aplicações industriais relacionadas às atividades florestais e, portanto, diversos novos cursos de capacitação foram desenvolvidos nessa perspectiva, os quais resultaram na concepção da Educação em Madeira.

Então, esse processo evolutivo educacional se consolidou a partir das tecnologias de processamento dos recursos 
florestais madeireiros em produtos de maior valor. Esse novo saber tem importância crescente no momento atual de maior conscientização, visto que as sociedades recentes vêm buscando por produtos mais sustentáveis obtidos a partir de manufaturas racionalizadas movidas por recursos de fácil obtenção e renovação e de baixos impactos ambientais.

A partir dessa perspectiva promissora, este artigo estabeleceu um amplo estado-da-arte sobre essas duas modalidades educacionais, tanto na perspectiva mundial quanto brasileira, para identificar suas características e realidades e, sobretudo, discutir suas dificuldades e oportunidades atuais. Os cursos contidos nessas duas áreas apresentaram inúmeras nomenclaturas, as quais foram identificadas para elucidar as carreiras específicas atualmente disponíveis. Um marco cronológico histórico foi estabelecido, tanto para a Educação Florestal quanto para a Educação em Madeira, para descrever a trajetória evolutiva dessa grande área profissional. Nesse âmbito, o artigo ainda produziu listas com os principais cursos em oferta no Brasil e discutiu o cenário atual desses dois tipos de formação profissional a partir de suas vocações e interesses estudantis.

\section{Metodologia}

Devido à abrangência do campo estudado, uma extensiva prospecção literária foi conduzida para compor e direcionar o estado-da-arte sobre a cronologia e o processo de evolução entre a Educação Florestal e a Educação em Madeira.

O roteiro de prospecção dos dados se baseou na metodologia considerada por Spinelli et al. (2019) em um estudo similar voltado para discutir as conquistas e futuras direções da Engenharia Florestal. Para isso, o presente estudo valeu-se da mesma sistemática de Spinelli que prospectou os dados, a partir dos sistemas de busca científica "Google Scholar", "Scopus" e "Web of Science", para suportar uma analise não estruturada qualitativa e representativa e cumprir os objetivos esperados de traçar os paralelos educacionais e evolutivos entre as áreas florestais e madeireiras.

A síntese literária se baseou em documentos científicos e técnicos e, sobretudo, em websites oficiais de universidades e instituições de ensino disponíveis em todo o mundo. A interpretação mais subjetiva desses materiais foi assegurada pela participação de autores com formações e experiências formais nas duas áreas em consideração, conforme indica a Tabela 1.

Tabela 1 - Formações e experiências dos autores deste artigo.

\begin{tabular}{ccc}
\hline Graduação & Título da pós-graduação: área & Experiências representativas \\
\hline Engenharia Industrial Madeireira & Doutor: recursos florestais & Construção em madeira, produtos florestais e indústria \\
Engenharia Industrial Madeireira & Mestra: recursos florestais & Economia florestal e produtos florestais \\
Engenharia Industrial Madeireira & Mestre: engenharia urbana & Bioenergia, produtos florestais e objetos de madeira \\
Matemática & Doutora: ciências dos materiais & Compósitos lignocelulósicos e ensaios não-destrutivos \\
Arquitetura e Urbanismo & Doutora: ciências ambientais & Bambu, mobiliário e produtos lignocelulósicos \\
Arquitetura e Urbanismo & Doutora: recursos florestais & Secagem da madeira e produtos lignocelulósicos \\
Engenharias Florestal e Civil & Doutor: engenharia de estruturas & Processamento da madeira e estruturas em madeira \\
\hline
\end{tabular}

Fonte: Autores.

A abordagem seguiu um raciocínio lógico que produziu uma narrativa sobre as características das formações em madeira e florestal e a respectiva evolução entre ambas as áreas. No roteiro utilizado, buscou-se identificar as vocações dessas carreiras e citar as suas principais escolas. O intuito dessa contribuição se sustenta na definição da evolução e caracterização das mesmas para um público formado por praticantes, acadêmicos e profissionais e, também, ingressantes e interessados.

Ocasionalmente, os autores se fundamentaram em não mencionar os cursos e as instituições com informações limitadas e inconclusas presentes em contribuições literárias informais e, ainda, naqueles websites visivelmente desatualizados, descontinuados e/ou desprovidos de dados básicos. Por questões institucionais e estratégicas influenciadas pelo dinamismo da 
educação superior, o rol de cursos apresentado poderá sofrer alterações ao longo das próximas décadas.

\section{Definições de Suporte aos Resultados}

\subsection{Características da educação florestal e sua formação}

A Educação Florestal intervém aos ecossistemas florestais para salvaguardar o equilíbrio no que diz respeito à preservação e utilização dos recursos florestais. De acordo com Spinelli et al. (2019), a convergência das ciências florestais e das operações florestais formam a base do curso de Engenharia Florestal, cuja definição não pode ser interpretada como uma única disciplina. A tabela 2 demonstra essa amplitude profissional formada por muitos ofícios. O Engenheiro Florestal possui uma formação ambiental abrangente, o que torna esse profissional capaz de lidar com os recursos das florestas. Logo, Santos (2006) descreveu que o manejo florestal, a silvicultura, a proteção florestal, a ciência e o meio ambiente, os produtos florestais e a tecnologia da madeira compõem os principais campos de atuação dessa área.

Além dessas inúmeras atividades (Tabela 2), um Engenheiro Florestal também pode trabalhar em universidades, colégios técnicos e escolas, especificamente, para desenvolver pesquisas e lecionar cursos e disciplinas de capacitação de pessoas. Ainda, Straka e Childers (2006) confirmaram que a consultoria florestal é um trabalho atrativo a esses profissionais, pois representa uma opção popular em razão de algumas oportunidades de emprego em projetos e empresas, apesar da maior demanda de especialização adicional para suprir diferentes ênfases.

Tabela 2 - Possíveis campos de trabalho para os Engenheiros Florestais.

Administração e gestão de empresas florestais

Administração de parques nacionais e reservas ecológicas

Assistência técnica e de pesquisa em atividades florestais

Projetos de instalação e manejo de reflorestamentos

Indústria da mecanização florestal (carregadores, tratores, implementos, transportadores, etc.)

Indústria química voltada às florestas (pesticidas, fertilizantes, etc.)

Instituições privadas (empresas, institutos de pesquisa, etc.)

Instituições públicas (ministérios, agências, institutos, etc.)

Planejamento florestal (biometria, inventário florestal, legislação, etc.)

Produção florestal (melhoramento genético, produção de sementes, produção de mudas, etc.)

Produtos florestais (óleos essenciais, resinas, polpa e celulose, madeira serrada, bioenergia, etc.)

Proteção florestal (patologias, controles biológicos, incêndios, etc.)

Secagem e preservação da madeira

Tecnologia e economia florestal

Fonte: adaptação de Poggiani (1980).

Diante dessa abrangência de ofícios (Tabela 2), a formação em Engenharia Florestal pode ser desenvolvida a partir de duas correntes disciplinares que envolvem diferentes perspectivas teórico-práticas.

A opção mista se volta à educação básica em Engenharia com a adição de conteúdos florestais específicas nos anos finais para a distinção desse curso frente a outras carreiras oriunda dessa disciplina principal. A segunda opção, mais específica, é designada pelo currículo básico em Ciências Florestais com reforço em componentes operacionais nas áreas de levantamento, estradas e práticas de colheita (Visser, 2007; Spinelli et al., 2019).

Em razão dessa multidisciplinaridade, o desenvolvimento da Educação Florestal permitiu a inclusão de áreas muito 
específicas, sobretudo, no âmbito da ciência e tecnologia da madeira. Diante da complexidade e especificidade das disciplinas desse contexto madeireiro, em um processo similar ao que ocorrera no passado durante a concepção da Engenharia Florestal como uma temática derivada da Engenharia Agronômica, a Engenharia Florestal desdobrou-se na formação do curso de Engenharia Industrial Madeireira. Essa partilha foi estimulada pela intensificação da Educação Florestal a partir de seu avanço tecnológico em suas múltiplas áreas.

\subsection{Características da educação em madeira e sua formação}

Os cursos de Educação em Madeira vêm se desenvolvendo com enfoques no processamento da madeira e na industrialização de quaisquer matérias-primas oriundas de uma floresta. Do mesmo modo que a Engenharia de Alimentos tipifica a transformação dos recursos agrícolas em alimentos processados, a Engenharia da Madeira surge como uma resposta produtiva à conversão dos recursos florestais em produtos lignocelulósicos.

A bagagem formativa abrangente dos Engenheiros Florestais contribuiu para o surgimento das primeiras escolas voltadas ao processamento da madeira, cujos sucessivos cursos de graduação são reconhecidos por diferentes designações como, por exemplo, Engenharia Industrial Madeireira, Engenharia da Madeira, Engenharia da Indústria Florestal, Engenharia do Processamento da Madeira, Engenharia dos Produtos Florestais, Tecnologia da Madeira, entre outros (De Araujo et al., 2017). Apesar dessas inúmeras nomenclaturas, o conteúdo integral desses distintos títulos é basicamente similar e atende as mesmas áreas tecnológicas essenciais à industrialização dos recursos florestais.

A graduação em Engenharia Industrial Madeireira atua no planejamento e desenvolvimento de projetos e processos para a produção em larga escala de bens duráveis e não duráveis a partir da madeira, cujas etapas de produção compreendem da colheita florestal até o processamento de seus recursos (Universidade Estadual Paulista, 2011). Especificamente, a Engenharia da Madeira refere-se aos tópicos dos recursos lignocelulósicos de caráter renovável, caracterização das matériasprimas florestais e o processamento dos recursos florestais em produtos industrializados. Portanto, essa moderna carreira inclui o desenvolvimento, teste e a produção de produtos florestais manufaturados a partir dos recursos madeireiros e nãomadeireiros de origem florestal.

Apesar da grande experiência sobre os produtos florestais, todos os produtos madeireiros e suas respectivas formas de processamento e transformação fabril compõem o objetivo essencial da Engenharia Industrial Madeireira. O Engenheiro Industrial Madeireiro possui uma formação múltipla, já que sua experiência profissional envolve distintas atuações (Tabela 3).

A Engenharia Industrial Madeireira absorveu os campos produtivos, em escala industrial, no que diz respeito aos estágios entre a colheita e o processamento das matérias-primas florestais, especialmente, da madeira e bambu, para a obtenção de polpa e celulose, madeira serrada e tratada, construções e estruturas (habitacionais, comerciais, industriais, rurais e de infraestrutura), painéis e compósitos engenheirados, móveis, embalagens e paletes, artigos domésticos, carvão vegetal e outros derivados desses materiais e seus resíduos. Além dessas opções, De Araujo et al. (2017) identificaram uma ampla variedade de soluções à base de madeira e bambu que incluem, por exemplo, brinquedos, ferramentas, decoração e ornamentos, suprimentos artísticos, bricolagem, artigos esportivos, suprimentos para escritório, instrumentos musicais e médicos e outros itens. 
Tabela 3 - Possíveis campos de trabalho para os Engenheiros Industriais Madeireiros.

Administração e gestão da indústria madeireira

Assistência técnica e de pesquisa em atividades madeireiras

Controle de poluição e gestão e reutilização de resíduos da indústria madeireira

Controle e gestão da qualidade na indústria madeireira

Industrialização da madeira (construções, embalagens, móveis, objetos, painéis, papéis, etc.)

Industrialização dos recursos florestais (óleos, resinas, polpa e celulose, madeira, bioenergia, etc.)

Instituições privadas (empresas, institutos de pesquisa, etc.)

Instituições públicas (ministérios, agências, institutos, etc.)

Licenciamento, inspeção e manutenção da indústria madeireira

Processamento, secagem, preservação e montagem de elementos à base de madeira

Processos produtivos e logísticos da indústria madeireira

Processos de obtenção de madeira (colheita, carregamento, transporte, descarregamento, etc.)

Projeto e desenvolvimento de produtos madeireiros e seus processos produtivos

Segurança no trabalho na indústria madeireira

Tecnologia e economia da madeira e do bambu

Fontes: adaptações de Universidade Federal do Paraná (2008), Universidade Estadual Paulista (2011), Universidade Federal do Espírito Santo (2013) e Universidade Federal de Pelotas (2019).

\section{Resultados}

\subsection{Cronologia histórica geral da educação superior florestal}

No Século XVIII, a demanda por um maior conhecimento sobre a madeira se tornou urgente, visto que poucos gerentes florestais eram realmente bons para serem solicitados por jovens ávidos por reter essa sabedoria (Fernow, 1907). Esse interesse aumentou ao longo do tempo, sendo representado por iniciativas globais.

Então, "escolas-mestre" vieram à tona e cada qual dependia exclusivamente de um "mestre-florestal", cujas iniciativas precedentes foram instituídas na Alemanha entre os Séculos XVIII e XIX. Em 1764, Hans von Zanthier desenvolveu uma escola em Wernigerode, a qual foi reinstalada em Ilsenburg. Patriarcas da silvicultura moderna, Heinrich Cotta e Georg Hartig, instituíram suas escolas-mestre em 1785 e 1789, respectivamente. Anos depois, a escola de Cotta se tornou uma instituição pública e, com isso, foi relocada em Tharandt. Esse maior interesse estatal sobre a Educação Florestal floresceu ao final do Século XVIII, já que o reino da Prússia começou a disponibilizar palestras de botânica aos interessados. Esse movimento ainda foi fortalecido pela oferta de um curso de Economia Florestal ministrado por um professor na Universidade de Berlim (Fernow, 1907). O pioneirismo germânico na Educação Florestal se confirmou pelo estabelecimento posterior desses treinamentos em outras nações. Esse processo expansionista se iniciou nos países vizinhos ao estado alemão e se espalhou pelas regiões mais distantes. Por vezes, os migrantes alemães foram os pioneiros florestais em outros países.

Com isso, os exemplos europeus em Educação Florestal se proliferaram a partir de 1800 em São Petersburgo na Rússia e na região da Boêmia do Império Austro-húngaro. Sequencialmente, essas escolas foram estabelecidas em 1823 em Estocolmo na Suécia, 1825 em Nancy na França, 1846 em Villaviciosa de Odón na Espanha, 1851 em Turim na Itália, 1862 em Evois na Finlândia, 1869 em Copenhagen na Dinamarca, 1875 em Kongsberg na Noruega, 1884 em Zurique na Suíça e em Egham no Reino Unido, 1886 em Lisboa em Portugal e 1894 em Vytina na Grécia (Fernow, 1907).

Historicamente, a Educação Florestal alcançou a Ásia em 1878 em Dehra Dun na Índia e 1883 em Nishigahara no Japão (Fernow, 1907). A China iniciou os seus primeiros cursos florestais somente no início do Século XX (Beijing Forestry 
University, 2015a). Os mesmos estão presentes em uma dezena de instituições de ensino superior (Murphy \& Roberts, 1988). Esse movimento educacional desembarcou na Oceania em 1910, especificamente, na Escola Florestal em Creswick na Austrália e, posteriormente, em 1970 na Escola Neozelandesa Florestal em Canterbury na Nova Zelândia (Sands, 2003).

Desde o momento em que os primeiros migrantes tocaram o solo norte-americano, a Europa contribuiu diretamente com o desenvolvimento do campo florestal naqueles territórios. No Canadá, a Educação Florestal iniciou formalmente a partir de cursos oferecidos em quatro universidades, das quais se encontram disponíveis desde 1907 em Toronto, 1908 em Fredericton, 1910 em Québec e 1921 em Vancouver (Paillé, 2003). Por sua vez, o programa educacional que inaugurou os estudos de Ciências Florestais nos Estados Unidos foi estabelecido pela Escola Florestal de Biltmore em Asheville em 1898 (Jolley, 2006). A seguir, faculdades florestais foram fundadas, por exemplo, em Yale, Cornell, Pensilvânia, Nova Iorque, Minnesota, Carolina do Norte e Oregon. DeSteiguer e Merrifield (1979) confirmaram que essa expansão educacional ocorreu a partir da década de 1960, possivelmente, pela maior preocupação ambientalista na América do Norte e, como efeito, pelo maior interesse nos cursos sobre as Ciências Naturais, como aqueles focados na área florestal.

Em 1909, o México se tornou a primeira nação latino-americana a estabelecer um curso de ensino superior no campo florestal, especificamente, em uma escola nacional (Eisenhauer, 1982). Meio século depois, esse processo foi repetido na América do Sul, já que a Educação Florestal chegou em 1952, tanto em Bogotá na Colômbia quanto em Santiago no Chile (Universidad Distrital Francisco José de Caldas, 2021; Universidad de Chile, 2021). Na década seguinte, esses cursos florestais também foram estabelecidos em Lima no Peru, Viçosa no Brasil e Missiones na Argentina (Universidad Nacional Agraria La Molina, 2011; Universidad Nacional de Misiones, 2017; Ministério da Educação, 2021). Mediante um suporte técnicofinanceiro formal da Organização das Nações Unidas em 1969, o Governo de Honduras instituiu a Escola Nacional de Ciências Florestais em Siguatepeque (Alvarado, 1998). Ao final da década de 1970, a Escola de Engenharia Florestal foi fundada em Cartago na Costa Rica (Tecnológico de Costa Rica, 2021).

Apesar do surgimento do treinamento técnico florestal durante o período de 1920 a 1930 no continente africano, a Educação Florestal em nível profissional foi introduzida somente ao final da década de 1950. As iniciativas foram implantadas em 1959 no Colégio Florestal em Monróvia, 1963 na Universidade de Ibadan na Nigéria, 1970 na Universidade de Makerere em Uganda, 1973 na Universidade de Dar es Salaam na Tanzânia e 1975 na Universidade de Dschang nos Camarões e na Escola Nacional Superior Agronômica na Costa do Marfim (Temu et al., 2006). Naquele momento, a Educação Florestal já estava praticamente difundida em todos os continentes. Atualmente, ao redor de 300 cursos florestais de distintos níveis de diplomação se perfazem ativos em todo o mundo (International Educational Specialists, 2021).

\subsection{Cronologia histórica dos cursos florestais no ensino superior brasileiro}

Em 1877, após um decreto promulgado anos antes, se estabeleceu o primeiro curso superior sobre Ciências Agrárias foi instalado como um curso de Agronomia no Imperial Instituto Bahiano de Agricultura, localizado em São Francisco do Conde, na Bahia. Os conhecimentos em Ciências Florestais foram lecionados em disciplinas de silvicultura do curso de Agronomia (Coleção de Leis do Império do Brasil, 1875; Poggiani, 1980; Capdeville, 1991; Ladeira, 2002).

Apesar as extensas florestas brasileiras, o curso de Engenharia Florestal foi introduzido somente em meados do Século XX, cuja iniciativa foi edificada em 1960 pela Escola Nacional de Florestas em Viçosa no estado de Minas Gerais (Ladeira, 2002; Bantel, 2007; Ministério da Educação, 2021).

No biênio inicial, as aulas foram lecionadas por professores do curso de Agronomia. Devido à falta de professores especialistas no ensinamento florestal, o Governo Brasileiro e a Organização das Nações Unidas formalizaram um convênio para a contratação de professores estrangeiros e, sobretudo, para a obtenção de apoio econômico para infraestrutura (Ladeira, 2002). Nesse início da década de 1960, o Brasil ainda vivenciou inúmeras turbulências causadas por greves, políticas 
inadequadas e falhas administrativas, as quais culminaram em atrasos e obstáculos no processo de estabelecimento e integração à universidade estatal mineira dessa primeira iniciativa formal voltada à Educação Florestal.

Diferentes fatores políticos impediram as metas estabelecidas pela Organização das Nações Unidas. Além disso, muitos professores estrangeiros não se adaptaram às crises e, persistentemente, tentaram encontrar soluções. Portanto, a transferência dessa Escola Florestal Nacional para Curitiba no estado do Paraná representou a solução final posta em prática em 1963. Integrada à Universidade Federal do Paraná, essa iniciativa foi reiniciada em seu ano letivo somente em 1964, devido à complexidade dessa transição estratégica. No entanto, o Governo do Estado de Minas Gerais aproveitou essa mudança para instituir uma segunda escola florestal, sob o nome de Escola Superior de Florestas, a qual se valeu dos moldes e das instalações da iniciativa anterior (Ladeira, 2002; Macedo, 2003). Com isso, o Brasil passou a desfrutar da oferta de duas escolas florestais estabelecidas, praticamente de maneira simultânea, nas duas principais regiões econômicas do país, Sudeste e Sul.

Apesar desses contratempos iniciais, inúmeros cursos florestais se proliferaram no cenário doméstico ao longo das décadas seguintes. De acordo com o Ministério da Educação (2021), existem 73 cursos de Engenharia Florestal em oferta em 64 instituições de ensino superior localizadas nas cinco diferentes regiões do Brasil, sendo 14 alternativas privadas (Tabela 4) e 59 públicas (Tabela 5). Em resumo, a iniciativa pública tem controlado cerca de $80 \%$ da atual Educação Florestal no Brasil. Esse dado sublinha e evidencia a existência dos esforços governamentais para proliferar as atividades florestais durante os últimos sessenta anos.

Tabela 4 - Instituições privadas com cursos ativos em Educação Florestal em 2021.

\begin{tabular}{ccc}
\hline Instituição & Oficialização & Região \\
\hline Faculdade de Ensino Superior e Formação Integral & 1992 & Sudeste \\
Universidade do Contestado & 1993 & Sul \\
Universidade Regional de Blumenau & 1995 & Sul \\
Faculdade de Ciências Sociais e Agrárias de Itapeva & 2002 & Sudeste \\
Faculdade de Rondônia & 2002 & Norte \\
Centro Universitário de Mineiros & 2002 & Centro-Oeste \\
Faculdade de Jaguariaíva & 2003 & Sul \\
Instituto Macapaense de Melhor Ensino Superior & 2003 & Norte \\
Universidade do Oeste de Santa Catarina & 2004 & Sul \\
Faculdade Pitágoras de Teixeira de Freitas & 2006 & Nordeste \\
Pontifícia Universidade Católica do Paraná* & 2008 & Sul \\
Pontifícia Universidade Católica do Paraná* & 2013 & Sul \\
Faculdade Orígenes Lessa & 2015 & Centro-Oeste \\
Faculdade de Ciências Sociais Aplicadas do Vale do São Lourenço & 2016 & Sudeste \\
\hline
\end{tabular}

* Instituições com cursos florestais em diferentes campi universitários. Fonte: adaptação de Ministério da Educação (2021). 
Research, Society and Development, v. 10, n. 7, e3010716084, 2021

(CC BY 4.0) | ISSN 2525-3409 | DOI: http://dx.doi.org/10.33448/rsd-v10i7.16084

Tabela 5 - Instituições públicas com cursos ativos em Educação Florestal em 2021.

\begin{tabular}{|c|c|c|}
\hline Instituição & Oficialização & Região \\
\hline Universidade Federal do Paraná & 1959 & Sul \\
\hline Universidade Federal Rural do Rio de Janeiro & 1963 & Sudeste \\
\hline Universidade Federal de Viçosa & 1964 & Sudeste \\
\hline Universidade Federal de Santa Maria* & 1971 & Sul \\
\hline Universidade Federal Rural da Amazônia* & 1971 & Norte \\
\hline Universidade de São Paulo & 1972 & Sudeste \\
\hline Universidade Federal do Mato Grosso* & 1974 & Centro-Oeste \\
\hline Universidade de Brasília & 1974 & Centro-Oeste \\
\hline Universidade Federal Rural do Pernambuco & 1975 & Nordeste \\
\hline Universidade Federal de Lavras & 1980 & Sudeste \\
\hline Universidade Federal de Campina Grande & 1980 & Nordeste \\
\hline Universidade Estadual Paulista & 1987 & Sudeste \\
\hline Universidade Federal do Amazonas & 1987 & Norte \\
\hline Universidade Estadual do Centro-Oeste & 1998 & Sul \\
\hline Universidade Federal do Espírito Santo & 1999 & Sudeste \\
\hline Universidade Federal do Acre* & 1999 & Norte \\
\hline Universidade Federal do Sergipe & 2001 & Nordeste \\
\hline Universidade Estadual do Mato Grosso & 2001 & Centro-Oeste \\
\hline Universidade Federal dos Vales do Jequitinhonha e Mucuri & 2002 & Sudeste \\
\hline Universidade Estadual do Amazonas* & 2002 & Norte \\
\hline Universidade Estadual do Amazonas* & 2003 & Norte \\
\hline Universidade Estadual de Santa Catarina & 2004 & Sul \\
\hline Universidade Estadual do Sudoeste da Bahia & 2005 & Nordeste \\
\hline Universidade Federal do Recôncavo da Bahia & 2005 & Nordeste \\
\hline Universidade Federal do Acre* & 2005 & Norte \\
\hline Universidade Federal de Santa Maria* & 2006 & Sul \\
\hline Universidade Federal do Pampa & 2006 & Sul \\
\hline Universidade Estadual de Goiás & 2006 & Centro-Oeste \\
\hline Universidade Estadual de Roraima* & 2006 & Norte \\
\hline Universidade Federal do Mato Grosso* & 2006 & Centro-Oeste \\
\hline Universidade Federal do Piauí & 2006 & Nordeste \\
\hline Universidade Federal de São Carlos & 2007 & Sudeste \\
\hline Universidade Federal do Tocantins & 2007 & Centro-Oeste \\
\hline Universidade Estadual do Amapá & 2007 & Norte \\
\hline Universidade Tecnológica Federal do Paraná & 2008 & Sul \\
\hline Universidade Estadual de Roraima* & 2008 & Norte \\
\hline Universidade Federal do Pará & 2009 & Norte \\
\hline
\end{tabular}


Tabela 5 (continuação) - Instituições públicas com cursos ativos em Educação Florestal em 2021.

\begin{tabular}{|c|c|c|}
\hline Instituição & Oficialização & Região \\
\hline Universidade Federal de Rondônia & 2009 & Norte \\
\hline Universidade Estadual do Mato Grosso do Sul & 2009 & Centro-Oeste \\
\hline Universidade Federal do Rio Grande do Norte & 2009 & Nordeste \\
\hline Universidade Federal de Minas Gerais & 2009 & Sudeste \\
\hline Universidade Federal de Goiás* & 2009 & Centro-Oeste \\
\hline Universidade Federal de Goiás* & 2009 & Centro-Oeste \\
\hline Universidade Federal do Mato Grosso do Sul & 2010 & Centro-Oeste \\
\hline Instituto Federal do Mato Grosso & 2010 & Centro-Oeste \\
\hline Instituto Federal do Norte de Minas Gerais & 2010 & Sudeste \\
\hline Universidade Federal Rural do Semiárido & 2011 & Nordeste \\
\hline Universidade Federal de Santa Catarina & 2012 & Sul \\
\hline Universidade Estadual do Pará* & 2012 & Norte \\
\hline Universidade Estadual do Pará* & 2013 & Norte \\
\hline Universidade Estadual do Pará* & 2013 & Norte \\
\hline Universidade Federal do Oeste do Pará & 2013 & Norte \\
\hline Universidade Federal de Alagoas & 2014 & Nordeste \\
\hline Universidade Federal de São João del Rei & 2014 & Sudeste \\
\hline Universidade Federal Rural da Amazônia* & 2014 & Norte \\
\hline Universidade Federal de Uberlândia & 2015 & Sudeste \\
\hline Instituto Federal de Minas Gerais & 2015 & Sudeste \\
\hline Instituto Federal de Rondônia & 2017 & Norte \\
\hline Universidade Federal do Sul da Bahia & 2018 & Nordeste \\
\hline
\end{tabular}

* Instituições com cursos florestais em diferentes campi universitários. Fonte: adaptação de Ministério da Educação (2021).

Desafortunadamente, o Ministério da Educação (2021) identificou que três cursos florestais particulares iniciados durante a última década já enfrentam processos de desativação, os quais vinham sendo ofertados em dois diferentes campi da Faculdade Cesumar na região Sul e no Centro Superior de Ensino e Pesquisa de Machado na região Sudeste. Isso indica um decréscimo atual de $1 \%$ na disponibilidade dessa modalidade de ensino em relação a 2017.

Com respeito à presença regional da Engenharia Florestal em 2021 (Tabelas 4 e 5), o Brasil concentrou: 19 cursos na região Norte ( 2 cursos em 2 diferentes instituições privadas e 17 cursos em 11 distintas instituições públicas), 16 cursos na região Sudeste ( 3 cursos em 3 instituições privadas e 13 cursos em 13 instituições públicas), 14 cursos na região Sul (6 cursos em 5 instituições privadas e 8 cursos em 7 instituições públicas), 13 cursos na região Centro-Oeste (2 cursos em 2 instituições privadas e 11 cursos em 9 instituições públicas) e, por fim, 11 cursos na região Nordeste (1 curso em 1 instituição privada e 10 cursos em 10 instituições públicas). Do exposto, somente a região sulista concentra uma proporção similar na oferta de educação superior florestal, já que os cursos sulistas se distribuem de modo praticamente similar entre as modalidades estatais e particulares. Contudo, o Sul ainda possui um déficit educacional perante outras regiões, apesar de sua forte vocação florestal.

Outras partes do país indicaram contrastes visíveis. O exemplo mais discrepante foi confirmado na região Nordeste, a qual obteve uma razão de 1/10 entre as instituições particulares e estatais. Essa incompatibilidade se reproduziu, similarmente, na região Norte, a qual oferece dois cursos privados em face às 17 opções públicas (Tabelas 4 e 5). Apesar dessas desarmonias, 
a forte atuação do governo brasileiro tem sido essencial para mitigar essa lacuna da Educação Florestal no âmbito privado, sobretudo, em estados com ampla necessidade de capacitação pessoal e altos índices de vulnerabilidade econômico-social. Essa disposição mais avultante do estado se tornou um ativo importante para o ensino superior brasileiro, já que busca elevar a baixa disponibilidade de cursos florestais a partir de opções públicas gratuitas nessas regiões de menor desenvolvimento.

Ainda, esse contraste entre a oferta dos cursos em instituições públicas e privadas foi notado na região Sudeste (Tabelas 4 e 5), a qual possui o maior patamar de desenvolvimento no país. Os estados sudestinos apresentam grandes áreas de plantio e unidades de conservação e proteção de florestas, entretanto, nem todas as microrregiões de vocação silvicultural, seja em estágio de crescimento ou consolidação, contemplam iniciativas de formação florestal. Essa ausência poderia ser suprida pela iniciativa privada, especialmente, naquelas microrregiões mais desenvolvidas e industrializadas.

No caso específico do Estado de São Paulo, ainda há uma visível ausência da Educação Florestal em nove das quinze regiões administrativas paulistas, sobretudo, nos setores regionais de vocação agrícola e elevada potencialidade silvicultural como, por exemplo, Assis, Araçatuba, Campinas, São José do Rio Preto e Presidente Prudente. Por sua vez, as regiões administrativas litorâneas, formadas pelo Vale do Paraíba e Litoral Sul, junto as suas significativas unidades de conservação de florestas nativas, também poderiam ofertar cursos florestais, ainda que disciplinas adicionais de proteção da fauna e flora e de conservação ambiental possam ser inseridas para suprir as demandas locais. Apesar da vocação cosmopolita da capital paulista e financeira de toda a sua região Metropolitana, a ausência de um curso florestal, independente do caráter institucional, se torna algo compreensível por conta da menor quantidade de áreas de cultivo nesses municípios. Porém, essa ausência contrastou com a maior frequência de cursos florestais em outras capitais federativas do país. O vasto maciço industrial ao longo da região Metropolitana paulista se torna um fator que justificaria a inserção de uma formação mais voltada ao processamento dos recursos florestais em produtos de maior valor agregado, a qual pode ser representada pela Engenharia Industrial Madeireira.

\subsection{Cronologia histórica geral da educação superior em madeira}

A partir de uma relação industrial, a Tecnologia da Madeira foi desenvolvida como um campo essencial relacionado à Educação Florestal, uma vez que se faz presente desde a década de 1880 nos Estados Unidos (Cummins, 1966). Utilizando a tecnologia de desenvolvimento de vanguarda para um futuro mais sustentável, a solução de problemas florestais se tornou uma meta da Universidade Estadual de Nova Iorque, cujo resultado instituiu a Faculdade de Ciências Ambientais e Florestais em 1911 (State University of New York, 2019). Pioneira na valorização do uso dos materiais renováveis, essa instituição concebeu o bacharelado em Ciência da Madeira em 1924, ou seja, dois anos após o surgimento do possível primeiro bacharelado nessa área na Universidade de Minnesota e três anos antes da Universidade Estadual do Oregon conforme citou Barnes (2007). Outros bacharelados em Ciência e Educação em Madeira são oferecidos por universidades norte-americanas desde 1935 no Idaho, 1939 em Iowa, 1943 na Pensilvânia, 1947 na Virginia Ocidental, 1949 na Carolina do Norte, 1965 na Virginia, 1965 em Massachusetts, 1972 no Maine, 1975 no Mississippi, 1997 em Purdue em Indiana e 2018 em Auburn no Alabama. Desde os anos 1970, a Escola Laney lidera o curso de Tecnologia da Madeira no estado da Califórnia (Laney College, 2021). O Canadá instaurou a Educação em Madeira, precisamente, em 1984 em Laval e 1995 na Columbia Britânica e, também, em Toronto, por meio de um processo de reestruturação curricular nacional iniciado durante os anos 2000 (Barnes, 2007; Armstrong, 2014). Logo, o uso crescente da madeira na América do Norte justificou esse rico cenário educacional.

$\mathrm{Na}$ Europa, a primeira iniciativa formal para o treinamento no processamento da madeira foi estabelecida na década de 1920, apesar de uma prévia existência da Educação em Madeira como disciplinas oferecidas pelas faculdades florestais alemãs situadas em Friburgo, Gotinga, Munique e Dresden (Kürsten, 2004). Ao final da Segunda Guerra Mundial, a Ciência da Madeira foi distinguida como uma disciplina acadêmica por seu considerável desenvolvimento (Gardner et al., 2005). Com isso, inúmeras escolas foram desenvolvidas para preencher essa lacuna do processamento das florestas em produtos, sobretudo, 
no período posterior à primeira revolução industrial.

Em meados da década de 1920, especificamente na Alemanha, a Universidade de Ciências Aplicadas de Rosenheim desenvolveu uma qualificação profissional sobre a indústria da madeira e o comércio da madeira por meio de quatro programas de bacharelado, dados por Engenharia Civil, Construção em Madeira, Tecnologia da Madeira e Engenharia de Interiores (Rosenheim University of Applied Sciences, 2013). Hoje, a Alemanha concentra cursos na Educação em Madeira sobre as áreas de tecnologia, ciência, engenharia e aplicação, os quais são disponibilizados em instituições em Hamburgo, Dresden, Rotemburgo, Lipa, Eberswalde, Hildesheim, Mosbach e Melle (Kürsten, 2004). No início da década de 1950, a Universidade Técnica de Munique estabeleceu formações sobre Ciência e Tecnologia da Madeira (Technische Universität München, 2021). Ao final da primeira década do Século XXI, a Universidade de Hamburgo passou a oferecer as formações em Indústria da Madeira e Utilização de Biorrecursos (Universität Hamburg, 2018).

Durante os anos de 1930, a Rússia e a França voltaram os olhos para a Educação em Madeira. Devido ao crescente potencial da indústria madeireira e das riquezas florestais na região do Mar Branco, a Universidade Técnica Estatal de Arkhangelsk se valeu dessa oportunidade para estabelecer múltiplas especializações e graduações com enfoque madeireiro (Arkhangelsk State Technical University, 2021).

No mesmo período, a Faculdade de Processamento Mecânico da Madeira foi criada pela Universidade Nacional Florestal Ucraniana para desenvolver a indústria madeireira local (Food and Agriculture Organization of the United Nations, 2001; Ukrainian National Forestry University, 2019). Nessa época, a Escola Superior da Madeira foi criada para oferecer o curso em Ciência e Tecnologia da Madeira em Nantes na França (École Superieure du Bois, 2019). Dois colégios francófonos para a Ciência da Madeira foram instituídos em Lion e Lorena na década de 1980 (École Catholique des Arts et Métiers de Lyon, 2013; Université de Lorraine, 2019).

A partir dos anos de 1950, a Educação em Madeira foi levada à Europa Oriental. A expansão se iniciou pela formação em Utilização da Madeira em Zvolen na Eslováquia (Technical University in Zvolen, 2017). Além disso, a carreira em Tecnologia da Madeira foi iniciada por duas instituições polonesas (Poznań University of Life Sciences, 2017; Widzial Technologii Drewna, 2019).

Ao final da década de 1950, a Universidade de Sopron na Hungria desenvolveu a formação em Engenharia Industrial Madeireira para compartilhar treinamento técnico sobre papel e celulose, indústria da madeira e tecnologia e design de interiores e produtos (University of Sopron, 2013). Nesse período, a Romênia também instituiu a Engenharia da Madeira em uma faculdade específica em Brasov (Transilvania University of Brasov, 2019). Na década seguinte, o curso de Ciência e Tecnologia da Madeira passou a ser oferecido na República Checa (Mendel University, 2019).

No início da década de 1970, outros três países europeus localizados nessa região oriental também receberam cursos diretamente ligados à Engenharia da Madeira, dentre os quais incluíram novas iniciativas acadêmicas na Eslovênia, Bulgária e Turquia (University of Ljubljana, 2021; University of Forestry, 2019; Hacettepe University, 2021). Nos anos 2000, a Turquia dobrou a sua oferta de opções a partir do estabelecimento da Engenharia da Madeira em outra universidade local (Muğla Sitki Koçman University, 2019).

$\mathrm{Na}$ Áustria, uma capacitação em Tecnologia da Madeira e das Fibras Naturais passou a ser lecionada desde os anos 1970 na Universidade de Recursos Naturais e Ciências da Vida de Viena (Universität für Bodenkultur Wien, 2019). Em 1995, a Universidade de Ciências Aplicadas de Salzburg desenvolveu a formação de Tecnologia dos Produtos Florestais e Construções em Madeira (Fachhochschule Salzburg, 2019). Logo após, o Instituto de Engenharia da Madeira e Tecnologia da Madeira passou a promover cursos de bacharelado em suas duas áreas prioritárias (Technische Universität Graz, 2019). Nos anos 2000, a Tecnologia da Madeira alcançou a Irlanda e a Suíça (Institute of Technology Sligo, 2019; Bern University of Applied Sciences, 2021). 
A partir de 2010, a formação voltada ao uso e transformação dos biorrecursos e biomateriais passou a ser disponibilizada na Escandinávia, sobretudo, na Finlândia e Suécia (Karelia University of Applied Sciences, 2019; Swedish University of Agricultural Sciences, 2020; Linnéuniversitetet, 2021). Em uma iniciativa singular, Portugal passou a oferecer uma capacitação em design de móveis a partir de 2012 (Escola Superior de Tecnologia e Gestão de Viseu, 2019).

Desde a sua concepção no início do Século XX, a Educação em Madeira demorou algumas décadas até desembarcar formalmente no continente asiático. Somente em 1947, a Universidade de Quioto no Japão estabeleceu o ensino em Ciências dos Biomateriais como uma carreira suplementar à Educação Florestal (Kyoto University, 2021). Seis anos depois, a Universidade de Quiuxu criou a formação em Ciências dos Biomateriais dentro do Departamento Florestal e dos Produtos Florestais como uma das inúmeras opções de sua Escola de Agricultura (Kyushu University, 2019). Em 1984, o sucesso das Ciências dos Biomateriais justificou o seu oferecimento pela Universidade de Tóquio (University of Tokyo, 2019).

A popularidade da formação em Ciência e Tecnologia da Madeira na Europa motivou a sua inserção na educação superior japonesa a partir da Universidade de Shizuoka no ano de 2008 (Shizuoka University, 2019) e, posteriormente, a Universidade de Ehime instituiu o novo curso de Ciências da Produção dos Biorrecursos em 2016 (Ehime University, 2019).

A China representou o segundo país asiático que recebeu a Educação em Madeira. Em 1954, a Universidade Florestal de Nanquim inovou na oferta abrangente de quatro carreiras modernas em sua Escola de Ciência e Engenharia dos Materiais, das quais compreendem a Ciência e Engenharia da Madeira, Construção de Estruturas de Madeira, Engenharia de Embalagens e a Ciência e Engenharia de Novas Energias (Nanjing Forestry University, 2021). Em 2002, a Universidade de Pequim usou uma estratégia similar ao promover múltiplas formações em sua Escola de Ciência e Tecnologia dos Materiais, cujas formações abarcam a Ciência e Engenharia da Madeira, Engenharia de Embalagens e Processamento Químico de Produtos Florestais (Beijing Forestry University, 2015b). Em Taiwan, a Universidade Nacional em Pingtung disponibiliza a formação em Ciência e Design da Madeira desde 1975 (National Pingtung University of Science and Technology, 2020).

No início da década de 1960, a Indonésia inseriu a formação em Produtos Florestais em dois institutos locais (Gadjah Mada University, 2019; Institut Pertanian Bogor University, 2019). Inspirada nessa carreira, a Universidade Nacional Florestal do Vietnã criou, também nessa época, a Tecnologia do Processamento dos Produtos Florestais (Vietnam National Forestry University, 2017).

Em 1982, a Tecnologia da Madeira foi inserida na Índia em sua Escola Politécnica de Kannur e, posteriormente, em outro colégio em Srinagar (Ettammal, 2020). Em 1987, a Malásia entrou no rol dos países que buscaram implantar a Educação em Madeira mediante o curso de Tecnologia dos Biorrecursos em uma de suas universidades locais (Universiti Sains Malaysia, 2017). Em uma estratégia para desenvolver a indústria sul-coreana de celulose e papel, instituições acadêmicas locais passaram a oferecer essa carreira. Inicialmente, a Engenharia do Papel foi inserida em Kangwon a partir de 1987 e a Ciência da Madeira e do Papel se tornou uma opção efetiva em Kyungpook a partir de 1996 (Kyungpook National University, 2019; Kangwon National University, 2021). Em 1999, a Engenharia Industrial da Madeira se materializou em uma opção moderna para os iranianos em Zabol (University of Zabol, 2019).

A Tailândia se tornou um dos últimos países asiáticos a receber a Educação em Madeira, cuja iniciativa passou a agregar as carreiras de Ciência e Tecnologia da Madeira e de Tecnologia da Celulose e Papel (Kasetsart University, 2010). Logo, a Educação em Madeira se proliferou nos países asiáticos em um processo similar ao vivenciado no continente europeu, ou seja, durante um período que consumiu algumas décadas.

De modo similar à Ásia, o continente africano passou a contar com a Educação em Madeira em meados do Século XX. Inicialmente, a Universidade de Stellenbosch viabilizou em 1956 o curso de Ciência da Madeira para a África do Sul (Stellenbosch University, 2019). Em 1975, a Universidade da Nigéria instituiu um novo curso sobre a Engenharia Agrícola e dos Biorrecursos (University of Nigeria, 2020). A partir da década de 1980, Gana implantou cursos de Tecnologia da Madeira 
em três diferentes universidades locais (Kwame Nkrumah University of Science \& Technology, 2018; Sunyani Technical University, 2019; University of Education - Winneba, 2019).

Por fim, a América Latina e o Caribe se tornaram as ultimas regiões a receber a Educação em Madeira. Na década de 1960, a Universidade de Bío-Bío desenvolveu o curso de Engenharia Civil em Indústrias da Madeira no Chile (Universidad del Bíobío, 2019). Visando o aproveitamento racional da floresta e a melhoria da qualidade na indústria florestal, a Universidade Nacional Experimental de Guaiana trouxe à Venezuela em 1988 a carreira de Engenharia de Indústrias Florestais (Universidad Nacional Experimental de Guayana, 2009).

Entre 1995 e 2005, o México optou em promover o curso de Engenharia em Tecnologia da Madeira em duas universidades (Universidad de Sierra Juárez, 2005; Universidad Michoacana de San Nicholas de Hidalgo, 2019). Nesse país, a Engenharia Florestal Industrial se tornou uma opção adicional voltada à industrialização florestal (Universidad Autónoma de Chapingo, 2018).

Desde os anos 2000, a Argentina vem compartilhando formações similares de nomenclaturas distintas que, por questões locais e institucionais, são designadas como Engenharia das Indústrias Florestais e Engenharia Industrial Madeireira (Universidad Nacional de Santiago del Estero, 2017; Universidad de Misiones, 2017). Simultaneamente, o Brasil passou a contar com esse curso de Engenharia Industrial Madeireira em quatro instituições públicas de diferentes estados situados nas regiões Sul e Sudeste (Ministério da Educação, 2021).

Em 2010, a Escola de Bermuda se tornou a primeira instituição a disponibilizar a Educação da Madeira na região caribenha a partir do curso de Tecnologia da Madeira (Bermuda College, 2021). Nos anos seguintes, o curso de Engenharia em Indústrias Agropecuárias e Florestais foi elaborado na Guatemala (Universidad de San Carlos de Guatemala, 2019). Em 2016, o curso de Engenharia em Processamentos Sustentáveis da Madeira foi concebido na Colômbia como uma solução moderna para a conversão mais racional dos biorrecursos em produtos de valor agregado (Universidad Tecnológica de Pereira, 2016). Nessa busca por cursos modernos, Honduras decidiu por ofertar a Engenharia em Indústrias e Negócios da Madeira como uma alternativa muito promissora frente às carreiras tradicionais (Universidad Nacional de Ciencias Forestales, 2018).

Apesar dessa pluralidade, a receptividade da Educação em Madeira ainda vivencia obstáculos que limitam a sua expansão e consolidação. Com isso, alguns cursos já deixaram de ser oferecidos, mesmo que temporariamente, no Equador, Chile, Costa Rica e Bolívia conforme sugeriram Berrios (1996), Consejo Nacional de Rectores (1987), Universidad Privada de Santa Cruz de la Sierra (2017), Universidad Tecnológica Equinoccial (2019) e Universidad de Chile (2019). Em contrapartida, algumas instituições já progridem rumo à Educação em Madeira por meio da disponibilização inicial de cursos de pósgraduação em áreas madeireiras ainda sem a presença de cursos de graduação nessas áreas. Os exemplos promissores se encontram no Uruguai, Peru, Nova Zelândia, Rússia, Holanda, Noruega, Namíbia e Marrocos. Com isso, a Educação em Madeira alcança uma popularidade em nível global.

\subsection{Cronologia histórica dos cursos em madeira no ensino superior brasileiro}

A Educação em Madeira foi iniciada no Brasil de maneira modesta e pontual. Inicialmente, a oferta perdurou por décadas na região Norte e, posteriormente, se concentrou nas regiões Sul e Sudeste (Tabela 6).

O estado do Amazonas, onde se encontra a floresta amazônica, recebeu a primeira formação madeireira do país. A iniciativa foi personificada pela Universidade Estadual do Amazonas e ocorreu ao final da década de 1970 a partir do oferecimento do curso de Tecnologia da Madeira, o qual era comum em outros países. A estratégia foi concebida para valorizar os potenciais das florestas nativas mediante boas práticas de gestão e manejo florestal. Ainda ativa na cidade de Manaus, essa formação precedente possui um currículo conveniente, embora ligeiramente mais compacto em comparação a qualquer curso de Engenharia tradicional existente no país. 
De modo assíncrono, a Educação em Madeira se expandiu nas regiões Sul e Sudeste, entre as décadas de 1990 e 2000, mediante o bacharelado em Engenharia Industrial Madeireira. Após um ano de propostas e estudos para suprir a demanda crescente por mão-de-obra capacitada na indústria madeireira sulista, o estado do Paraná foi pioneiro no oferecimento dessa modalidade profissional, por meio de sua principal instituição de ensino superior, ainda durante o desfecho do Século XX.

Sequencialmente, os governos estaduais de São Paulo, Rio Grande do Sul e Espírito Santo voltaram as suas atenções para essa nova carreira. Logo, esse moderno curso passou a ser oferecido em universidades públicas desses estados, mediante processos expansionistas da Educação Superior brasileira durante os anos 2000, como uma tática de capacitação profissionalizante em suas regiões agroflorestais. Essa estratégia expansionista foi liderada pelo governo paulista, basicamente, como uma resposta afirmativa à tentativa de desenvolver uma nova indústria regional no Sudoeste desse estado. Nessa região, os menores níveis de desenvolvimento humano e industrialização e a maior concentração de florestas plantadas foram as justificativas para a oferta dessa formação, sobretudo, para fomentar a economia regional e criar empregos e empresas para agregar valor aos produtos florestais oriundos de suas atividades agroflorestais. As vocações florestais regionais representaram justificativas congêneres na oferta da Engenharia Industrial Madeireira nas outras duas propostas.

De fato, cinco estados de três regiões já oferecem a Educação em Madeira no país (Tabela 6), a qual é inteiramente predominada pelo ensino público superior. Além da formação precursora em Tecnologia da Madeira na região amazônica, o Brasil ainda dispõe dos quatro cursos de Engenharia Industrial Madeireira, cujas presenças incluem regiões silviculturais e madeireiras relevantes ao país. O atual panorama sustenta que os esforços governamentais para a promoção da madeira no Brasil, mesmo que pontuais, são formalizados pela oferta de cursos voltados ao propósito da madeira.

Tabela 6 - Instituições públicas com cursos ativos em Educação em Madeira em 2021.

\begin{tabular}{ccc}
\hline Instituição & Oficialização & Região \\
\hline Universidade Estadual do Amazonas & 1978 & Norte \\
Universidade Federal do Paraná & 1998 & Sul \\
Universidade Estadual Paulista & 2003 & Sudeste \\
Universidade Federal de Pelotas & 2005 & Sul \\
Universidade Federal do Espírito Santo & 2006 & Sudeste \\
\hline
\end{tabular}

Fonte: adaptação de Ministério da Educação (2021).

Devido à importância das atividades de extração e beneficiamento da madeira nos estados mais austrais, tanto o Paraná quanto Santa Catarina já desfrutaram a oferta da Engenharia Industrial Madeireira em instituições particulares. Encorajadas pela ação pública demonstrada na Tabela 6, a Universidade do Planalto Catarinense e o Centro Universitário de União da Vitória, respectivamente em Santa Catarina e no Paraná, ofereceram o curso de Engenharia Industrial Madeireira dentre as suas opções de carreira ao longo dos anos 2000, conforme sinalizou o Ministério da Educação (2021). Nessa época, a Universidade Estadual do Pará ainda desenvolveu um curso gratuito singular, intitulado Tecnologia Agroindustrial com ênfase em Madeira e Alimento, para valorizar os recursos florestais e agrícolas. Atualmente, tanto as duas opções particulares sulistas quanto o curso público paraense, por razões desconhecidas e futuros incertos, se encontram indisponíveis aos brasileiros.

Atualmente, não existem investimentos com respeito à expansão da Educação em Madeira para outros estados e regiões brasileiras. De fato, a promoção e proliferação dessa moderna carreira sofrem com diversos obstáculos. De acordo com Pereira (2020), a universidade brasileira vem sofrendo com cortes de recursos orçamentários, contingencia nos fundos para a pesquisa e redução de bolsas de estudo. Desse modo, a expansão iniciada nos anos 2000, conforme evidenciou a Tabela 6, sofreu uma completa interrupção nos anos 2010 e, com isso, a perspectiva futura da década de 2020 não se mostra promissora. 
Por outro lado, devido às oportunidades do agronegócio e às potencialidades da silvicultura, o cenário nacional se mostra ávido pelas formações voltadas à produção e ao processamento fabril dos recursos renováveis, como as carreiras abrigadas na Educação Florestal e em Madeira, em tempos de uma constante procura por soluções mais sustentáveis de menor prejuízo ambiental. Por isso, a ausência de pós-graduação em Educação em Madeira é perceptível e necessária, razão pela qual alguns programas de Ciências Florestais já incluem, mesmo que pontualmente, estudos e linhas de pesquisa voltadas à Ciência e Tecnologia da Madeira. Logo, novos programas deverão ser projetados e implantados para que a conexão entre a ciência e a indústria madeireira seja oficialmente desenvolvida e estimulada tecnologicamente. Em paralelo, o ensino técnico em madeira prove capacitações profissionalizantes à força de trabalho fabril. No âmbito das escolas técnicas públicas, dez instituições oferecem cursos de silvicultura e florestas e outras doze oferecem cursos de móveis de madeira, design de móveis de madeira e celulose e papel. Os esforços governamentais ao ensino técnico são igualmente formais àqueles para as universidades, mesmo que ainda pontuais, pois geram meios para o treinamento da força de trabalho em diferentes frentes. O ensino técnico particular é mais ativo, já que 40 instituições dispõem de 19 cursos ativos em celulose e papel, design de móveis, carpintaria e movelaria.

\section{Discussão}

Essa seção foi organizada em três pontos essenciais para abordar as visões sobre os cursos e suas nomenclaturas utilizadas, seu processo evolutivo e os cenários e perspectivas dessas duas Educações observadas.

\subsection{Evolução da carreira florestal à madeireira}

A área florestal exerce um papel importante para as economias globais como, por exemplo, de nações europeias e norte-americanas, especialmente, a partir das atividades de exploração da madeira marcada por múltiplos setores e empregos (McDaniel et al., 2012; Food and Agriculture Organization of the United Nations, 2001, 2020). Diante do ambiente favorável, seja em aspectos sociais ou econômicos, a estrutura educacional desses países integra as bases de manufatura e formação.

Essa perspectiva foi confirmada pela constatação de Seixas (1989) sobre a Educação Florestal na América do Norte, onde as típicas escolas florestais, em um processo de adaptação ao mercado de trabalho regional, usualmente oferecem as disciplinas mediante uma organização semanal de 20 horas para escopos ambientais, 6 horas para pontos essenciais e 4 horas para tópicos optativos. Outra questão respondida por essa estrutura educacional se refere às amplas presenças e flexibilidades. De acordo com Paillé (2002) e ForestryUSA (2019), há uma considerável oferta da Educação Florestal no ensino superior desse continente, a qual inclui 53 instituições em 37 estados norte-americanos e 8 instituições em 5 províncias canadenses. Além do volume institucional representativo, a vasta quantidade de formações inseridas no contexto florestal se torna outro fator que justifica a importância dessa atividade, já que uma única instituição pode oferecer múltiplas formações. Nesse contexto, Seixas (1989) confirmou que a Universidade Estadual do Oregon disponibiliza, em nível de graduação, quatro diferentes cursos florestais que incluem a Engenharia Florestal, Gestão Florestal, Gestão de Recursos Recreacionais e Tecnologia de Produtos Florestais.

Essa multiplicidade é vista até no México, onde os cursos de Engenharia Florestal, Engenharia em Restauração Florestal, Engenharia Florestal Industrial, Engenharia em Recursos Naturais Renováveis e Engenharia do Desenvolvimento Agroflorestal se fazem presentes em uma mesma instituição (Universidad Autónoma de Chapingo, 2018). No entanto, essas formações diversificadas não se limitam à América do Norte.

Na Bulgária, a Universidade Florestal tem oferecido os cursos de Design de Paisagem Urbana, Silvicultura e Engenharia Florestal para estudantes do sudeste europeu (University of Forestry, 2019). No continente africano, a Silvicultura

e Gestão Florestal e Ciência e Tecnologia da Madeira são carreiras para alunos de Gana (Kwame Nkrumah University of Science \& Technology, 2018). 
A Engenharia Florestal, Sistemas de Informação Geográfica Silviculturais, Proteção Florestal, Silvicultura Urbana e Prevenção de Fogos em Florestas surgem como alternativas para os estudantes da Universidade Florestal de Pequim (Beijing Forestry University, 2015c). Um quadro similar é perceptível no Japão, dada a disponibilidade dos distintos cursos em Ciências Ambientais e Florestais, Biociências Florestais, Ciências dos Biomateriais e Ciências dos Biorrecursos Sustentáveis (Kyushu University, 2019). Na Tailândia, uma instituição local oferece as carreiras de Engenharia Florestal, Tecnologia da Celulose e Papel, Ciência e Tecnologia da Madeira e Silvicultura Social (Kasetsart University, 2010). A Universidade Florestal do Vietnã também apresenta frentes diferenciadas que incluem a Engenharia Florestal, Silvicultura, Proteção Florestal, Arquitetura Paisagística e Gestão dos Recursos Florestais (Vietnam National University of Forestry, 2017).

Essa amplitude a respeito das múltiplas formações e ofertas gera duas importantes questões. O primeiro fato é identificado pela existência de visões mais densas sobre campos mais específicos, em detrimento ao conhecimento mais generalista, que diferem as formações norte-americanas dos cursos florestais tradicionais mais comuns em outros países. Outro ponto se refere às reduções das cargas horárias e atribuições profissionais nessas opções específicas que, essencialmente, privilegiam o aprofundamento das noções e conhecimentos.

Essa maior especialização sobre os campos-alvo proporciona uma formação acadêmica sólida e, também, uma experiência de conhecimento perspicaz, para cada especialidade profissional, sobre os respectivos temas de observação e estudo. Apesar do mercado de trabalho ser possivelmente mais escasso aos especialistas, isso poderia complicar a inserção desses profissionais especializados em vagas mais generalistas. Em contraste, as formações adensadas permitem um maior reconhecimento e adesão aos cargos mais específicos e, ainda, estimulam a criação de vagas características em empresas que almejam bons desempenhos a partir de profissionais de certas especialidades e aptidões; características as quais um trabalhador generalista teria maior dificuldade, já que funções específicas demandam maiores tempos de adaptação e aprendizagem.

Paralelamente, as carreiras de Engenharia têm sido fragmentadas em todo o mundo para alcançar maiores graus de especialização profissional em áreas determinadas. Esse fato é claramente constatado na Engenharia Civil que, ao longo do tempo, tem sido subdividida em cursos específicos. Por consequência, as titulações da Engenharia Civil se derivam em áreas de Materiais, Infraestrutura, Transportes, Mineração, Estrutural, Agrimensura, Hidráulica, Elétrica, Acústica, Forense, Geotécnica, Geoespacial, Naval, Ambiental e Urbana.

Essas subdivisões são preponderantes ao desenvolvimento de diferentes campos e, com isso, a Engenharia Civil voltou ao seu propósito maior, o qual envolve o projeto e desenvolvimento dos sistemas construtivos e de seus elementos. Portanto, as novas direções também se desenvolveram a partir de um maior enfoque e aplicação de seus estudos, o que contribuiu para a criação dessas novas carreiras contemporâneas. Na prática e teoria, essas soluções modernas geralmente se completam umas às outras.

Logo, esse anseio por carreiras mais especialistas possibilitou o florescimento da Educação em Madeira entre os Séculos XIX e XX, tal como ocorreu na Engenharia Civil e seus cursos correlatos. A origem da área madeireira a partir da Engenharia Florestal - que vem a ser um fiel desdobramento da Engenharia Agronômica - se converte no processo de maior especialização e refinamento dos objetivos de ambos os campos profissionais.

No que diz respeito a essa evolução, a Engenharia Florestal advém da Engenharia Agronômica que, em um processo similar ao da Engenharia Civil, se subdividiu em campos específicos que também se tornaram cursos específicos como a Ecologia, Economia Rural, Silvicultura, Produção Vegetal, Fisiologia, Genética, Entomologia, Bioenergia, Meteorologia, Zootecnia, Ciências Agrárias, Ciências dos Alimentos, Ciência Animal, etc. Por isso, os cursos tradicionais em Engenharia têm se voltado para esse aprofundamento em seus temas mais relevantes, já que contemplam estudos amplos e campos distintos.

Na conjuntura da Educação Florestal, as ciências, engenharias e tecnologias derivadas desse contexto profissional surgiram a partir de seus campos relacionados e atribuições de carreira, conforme listou a Tabela 2. Com o tempo, diversos 
campos alcançaram maior destaque. Silvicultura, conservação, reparação, manejo, produtos e processamentos se tornaram as principais experiências na área florestal. Logo, a Educação Florestal se organiza e divide em campos de estreitas relações.

Devido às diferentes atribuições e importâncias econômicas para a indústria, os produtos florestais e respectivos processos de produção foram elevados a outra subdivisão. Os crescentes benefícios da madeira e as preocupações ambientais fortaleceram o desenvolvimento da área dos biorrecursos renováveis e seus processamentos, a qual se encontra em voga nas ultimas décadas. No cenário exposto, a Educação Florestal se volta aos campos principais, ou seja, às atividades realizadas diretamente no ambiente florestal (matas nativas e plantios silviculturais), enquanto que a Educação em Madeira reúne experiências posteriores a esse contexto e se aprofunda na direção dos produtos e processamentos dos produtos florestais, conforme identificou a Tabela 3.

Na maioria das universidades norte-americanas, a Educação em Madeira é lecionada em um ou mais departamentos, os quais incluem Engenharia (Agronômica, Civil, etc.), Arquitetura e Ciências da Madeira (Produtos Florestais, Biorrecursos, etc.). Em algumas unidades, esses departamentos se apresentam de modo conjunto ou independente (Testa \& Gupta, 2004).

$\mathrm{Na}$ China, as formações disponíveis incluem a Ciência e Engenharia da Madeira, Construção de Estruturas de Madeira, Engenharia de Embalagens, Ciência e Engenharia de Novas Energias e Processamento Químico de Produtos Florestais (Nanjing Forestry University, 2021; Beijing Forestry University, 2015b). A Malásia se voltou às formações de Ciência da Madeira e do Papel, Engenharia do Papel e Tecnologia dos Biorrecursos (Universiti Sains Malaysia, 2017; Kangwon National University, 2021; Kyungpook National University, 2019). No Japão, existem cursos diferenciados voltados às Ciências Ambientais da Bioprodução, Ciências dos Biomateriais, Ciências dos Biorrecursos Sustentáveis e Ciências da Produção dos Biorrecursos (Ehime University, 2019; Kyushu University, 2019).

Na Alemanha, a Educação em Madeira se desdobra em múltiplas qualificações que incluem a Tecnologia da Madeira, Construção em Madeira, Engenharia de Interiores, Ciência da Madeira, Indústria da Madeira e Utilização de Biorrecursos (Rosenheim University of Applied Sciences, 2013; Universität Hamburg, 2018; Technische Universität München, 2021).

Com isso, a Educação em Madeira caminha para se tornar uma grande área, compreendida como uma derivação da Educação Florestal, por sua ampla disponibilidade de carreiras específicas em todo o mundo.

\subsection{Nomenclaturas dos cursos oferecidos}

Inicialmente, muitas designações foram identificadas em relação aos cursos de graduação em Educação Florestal e Educação em Madeira. Apesar da ausência de padronização a respeito dessas titulações e carreiras, uma parte considerável dos programas de estudos dessas formações seguiu conteúdos e objetivos similares.

Mesmo com essas similaridades de currículo, as especificidades direcionaram os propósitos e objetivos do curso para:

- Disciplinas multidisciplinares: recursos biológicos, produção de biomassa, propriedades dos materiais, anatomia da madeira, impactos ambientais, sustentabilidade, produtos florestais, biotecnologia, uso de biorrecursos, reutilização de resíduos, entre outros;

- Tópicos disciplinares específicos: construção em madeira, produtos derivados de madeira, movelaria, produção de papel e celulose, design e desenvolvimento da indústria da madeira, serração, biorrefinaria e bioprocessos, processamento da madeira, biocombustíveis, etc.

$\mathrm{Na}$ Educação Florestal, as nomenclaturas usuais para os cursos de graduação correlacionados seguiram as seguintes terminologias: Engenharia Florestal, Silvicultura, Ciências Agrárias e Florestais, Ciências Florestais, Tecnologia Florestal, Recursos Florestais, Recursos Ambientais e Florestais, Recursos Naturais, Gestão dos Recursos Naturais, Recursos Naturais e Ambientais, Ciências Naturais e da Vida, entre outros.

Diante das abordagens mais amplas da Engenharia Florestal, as universidades europeias e norte-americanas criaram a 
Educação em Madeira com enfoque em produtos, processos e indústrias, cujos cursos de graduação de longa duração, ou major courses, têm sido usualmente denominados, conforme identificaram De Araujo et al. (2017), como Tecnologia da Madeira, Engenharia da Madeira, Engenharia Industrial Madeireira, Engenharia das Indústrias Florestais, Engenharia do Processamento da Madeira e Engenharia dos Produtos de Madeira.

No entanto, existem inúmeros objetivos e propósitos em relação aos tópicos da Educação em Madeira. Essa situação resulta na existência de exemplos semelhantes com nomenclaturas um tanto diferentes. Logo, outras denominações também são utilizadas para esses cursos (de graduação ou bacharelado) como, por exemplo, Ciência da Madeira, Ciência e Design da Madeira, Engenharia Civil da Indústria Madeireira, Tecnologia dos Produtos Florestais, Processamento de Produtos de Madeira, Gestão da Madeira, Construção em Madeira, Biomateriais Sustentáveis, Biomateriais e Embalagens, Ciências dos Biomateriais Florestais, Produção dos Biorrecursos, Bioprodutos Sustentáveis, Materiais de Biorrecursos, Biorrecursos e Bioambiente, Materiais Renováveis, entre outros.

Dentre essas opções de formação, poucas disciplinas claramente se diferem entre si. Assim, as diferentes disciplinas são engendradas por nomenclaturas bastante específicas. As especificidades foram criadas para detalhar aquelas abordagens mais particulares, as quais são caracterizadas por cursos de menor duração (minor courses). O encurtamento no conteúdo e quantidade de disciplinas são as razões para essas opções acadêmicas, cujas nomenclaturas mais populares foram identificadas por Produtos Florestais, Construção em Madeira, Indústria da Madeira, Processamento da Madeira, Exploração Madeireira, Móveis, Design de Mobiliário, Engenharia do Papel, Tecnologia da Polpação, Biorrefinaria, Carpintaria, Marcenaria, etc. Em resumo, esses cursos compactos são usualmente baseados em tópicos e assuntos essencialmente específicos, cujas abordagens envolvem, parcialmente, os produtos e processos correlatos à área florestal-madeireira. Conforme sugeriram Gardner et al. (2005), essa amplitude de carreiras é atribuída ao vasto desenvolvimento da Ciência da Madeira como uma disciplina moderna.

De modo geral, as universidades basicamente têm seguido uma estrutura educacional similar, cujas nomenclaturas e disciplinas de graduação se diferenciam ligeiramente entre cada departamento e país. No âmbito dos cursos de pós-graduação, as ofertas, quando existentes, possuem consideráveis similaridades às formações disponíveis em nível de graduação.

\subsection{Cenários e perspectivas da educação florestal e da educação em madeira}

Apesar do notável desenvolvimento da Ciência da Madeira após a Segunda Guerra Mundial, o seu declínio se iniciou nos anos 2000. Esse fato gerou discussões entre os cientistas sobre o futuro dos estudos e programas relacionados à Educação em Madeira (Gardner et al., 2005). Por conta de razões diversas (Tabela 7), esse declínio se faz presente em qualquer carreira do ensino superior. De acordo com Silva et al. (2020), a evasão discente está entre os principais gargalos do ensino superior em todo o mundo, cujo reflexo expõe as falhas nas políticas de apoio estudantil. 
Tabela 7 - Principais justificativas da evasão discente no ensino superior.

Razões identificadas acerca da desistência dos estudantes em diferentes cursos e ambientes universitários

Falta de perspectiva na carreira

Baixo nível de comprometimento com o curso

Baixa participação em atividades acadêmicas

Baixo desempenho escolar

Instalações precárias

Falta de apoio familiar

Necessidade da realização simultânea de atividades acadêmicas, profissionais e pessoais

Formação anterior deficitária

Fontes: adaptações de Pereira et al. (2011), Durso e Cunha (2018), Simões e Custódio (2020) e Silva et al. (2020).

Há uma redução constante nos programas ativamente engajados no ensino de Engenharia da Madeira e um consequente declínio no número de alunos expostos ao design em madeira, revelando um impacto negativo na indústria de produtos de madeira dos Estados Unidos (Testa \& Gupta, 2004). Uma situação similar tem sido observada na diplomação tradicional de silvicultura no Canadá, Nova Zelândia e Reino Unido, cuja razão identificada envolve a crise global que enfrenta a educação profissional dos silvicultores (Innes \&Ward, 2007; Kanowski, 2008; Searle \& Bryant, 2009).

Essa diminuição também tem sido observada no Brasil. Conforme demonstrou a Tabela 8, os cursos de Engenharia Florestal e Engenharia Industrial Madeireira em oferecimento, na condição de ensino público gratuito, pela Universidade Federal do Paraná (Tabelas 5 e 6) sofreram um perceptível decréscimo na competição de candidatos por vaga oferecida. Em um período decênio recente, o interesse dos estudantes sofreu uma forte queda de $40 \%$ na formação florestal e retrações explícitas de $23 \%$ e $30 \%$ nas opções diurnas e noturnas da carreira voltada à indústria madeireira.

Tabela 8 - Competição de candidatos por curso em oferta na Universidade Federal do Paraná.

\begin{tabular}{clll}
\hline Curso de graduação & Período & Ano & Competição (candidato/vaga) \\
\hline Engenharia Florestal & Diurno & 2009 & 5,48 \\
Engenharia Florestal & Diurno & 2018 & 3,34 \\
Engenharia Industrial Madeireira & Diurno & 2009 & 3,50 \\
Engenharia Industrial Madeireira & Diurno & 2018 & 2,71 \\
Engenharia Industrial Madeireira & Noturno & 2009 & 4,61 \\
Engenharia Industrial Madeireira & Noturno & 2018 & 3,25 \\
\hline
\end{tabular}

Fontes: adaptações de Mundo Vestibular (2009) e Universidade Federal do Paraná (2015).

Esse declínio tem sido vivenciado em outra importante instituição pública que disponibiliza a Educação em Madeira no país. De acordo com Silva et al. (2020), dos 262 discentes que ingressaram na Engenharia Industrial Madeireira do campus de Itapeva da Universidade Estadual Paulista entre 2003 e 2013, o número médio de evasão discente foi de 8,6 alunos/ano a um tempo médio de permanência de 1242 dias. Os autores ainda confirmaram que algumas variáveis influenciaram a evasão como, por exemplo, o número de tentativas para o ingresso ao curso, participação em cursinhos preparatórios, classificação do discente no processo de seleção e a necessidade do candidato ter uma atividade remunerada desde a inscrição no vestibular.

Porém, cabe ressaltar que o declínio no interesse pelas carreiras florestais e madeireiras ocorreu simultaneamente ao processo de expansão educacional no Brasil. O número extenso de cursos de graduação e a maior proliferação de universidades 
e formações acadêmicas em regiões remotas e vulneráveis compuseram esse processo expansionista ocorrido entre as décadas de 2000 a 2010. Em consequência, a ambição por carreiras mais tradicionais e a possibilidade de estudo em locais próximos aos domicílios dos estudantes se resumiram nos fatores redutores mais explícitos da queda sofrida nos cursos existentes, dentre os quais se incluíram as carreiras florestais e madeireiras. Essa proliferação do ensino superior brasileiro foi retratada na literatura. Enquanto Barros (2015, p.361) confirmou que o Brasil vivenciou um “...crescimento da oferta de vagas, sobretudo no sistema superior privado...", Saviani (2010, p.11) detalhou que essa conjuntura recente foi caracterizada pelos “...diferentes tipos de instituições universitárias oferecendo cursos os mais variados em estreita simbiose com os mecanismos de mercado.". Em compensação, a menor popularidade da Educação em Madeira no Brasil é atribuída à presença recente de suas carreiras no país e, simultaneamente, à visível ausência de ações de promoção das mesmas à população. Essa perspectiva foi assegurada por De Araujo et al. (2019) em seu estudo representativo sobre o setor produtivo brasileiro de casas de madeira, cujos achados confirmaram o atual desconhecimento do curso de Engenharia Industrial Madeireira em dois-terços dos produtores avaliados.

Como esse possível desapreço pela formação em madeira é percebido dentro de um setor produtivo importante à cadeia florestal-madeireira, existe a possibilidade clara que outros setores correlatos, além de uma considerável parcela da população, ainda desconheçam esse curso e as suas aptidões. Logo, surge a necessidade urgente de estímulos governamentais para a promoção e divulgação dessa e de outras carreiras contempladas na Educação em Madeira no âmbito nacional como uma estratégia afirmativa de capacitação pessoal para os múltiplos setores envolvidos; essa interferência se faz necessária por conta das demandas identificadas por De Araujo et al. (2019), onde um terço do setor produtivo de casas de madeira não possui mão-de-obra capacitada, apesar de $85 \%$ desse público avaliado ter declarado a demanda por profissionais graduados. Assim, essa necessidade efetiva pode se estender facilmente a quaisquer outros setores madeireiros.

Como as indústrias florestais e madeireiras estão entre as mais importantes e promissoras em todo o mundo, há uma demanda instantânea para o fomento de alternativas que cessem essa contração educacional e estimulem a sociedade pela promoção da madeira e seus benefícios como a sustentabilidade e renovabilidade de suas fontes, multiplicidade de produtos derivados, altos níveis de processamento fabril e reciclabilidade de resíduos, entre outros. Para isso, Searle \& Bryand (2009) preveem que o futuro solicitará um aumento das plantações e uma maior ênfase nas fazendas florestais que, consequentemente, dependerão de uma representativa força de trabalho capacitada para movimentar as atividades florestais e impulsionar os variados setores da indústria da madeira.

Uma rota oportuna para "re-atrair" os estudantes para essas carreiras em perspectiva pode envolver a remodelação da atual Engenharia Florestal, concedendo maior atenção aos escopos relacionados às atividades estritamente realizadas no ambiente florestal e às disciplinas inovadoras sobre o melhoramento de espécies direcionado para a silvicultura de rápido crescimento e a produção de madeira de qualidade para fins industriais. Outro caminho simultâneo incide na maior valorização dos cursos relacionados à madeira e suas atividades industriais de processamento e beneficiamento, como a Engenharia Industrial Madeireira, cujo currículo agrega as operações entre a colheita florestal e a manufatura de produtos florestais.

Apesar do declínio nas carreiras florestais e madeireiras, um futuro promissor está voltando por meio das mudanças nos hábitos de consumo para um futuro mais saudável como, por exemplo, a solicitação crescente de produtos mais verdes e sustentáveis, utilização de matérias-primas naturais de fácil renovação e obtenção, setores industriais enraizados na economia circular e produção mais limpa a partir de processos mais inteligentes, conjuntamente, para reduzir a poluição e degradação ambiental causada pelo uso de materiais não-renováveis como os metais, plásticos, cimento, etc.

A intensificação da utilização florestal como fonte de matéria-prima contínua e a valorização dos bens manufaturados em madeira como alternativas mais saudáveis estarão no centro das atenções no futuro próximo. Esse avanço já se materializa, inclusive, no consumo de aplicações mais definitivas como, por exemplo, a pré-fabricação da construção em madeira para produzir diferentes casas unifamiliares e edifícios multipavimentos conforme listados por Natterer et al. (2004), Benoit \& 
Paradis (2008), Langenbach (2008), Smith \& Frangi (2008), van de Kuilen et al. (2010), De Araujo et al. (2016a;2016b), etc. Ainda, uma frente auspiciosa deve ser orientada pela bioeconomia e bioprodutos como, por exemplo, biopolímeros feitos com celulose para reduzir os plásticos à base de petróleo, conforme citado por Pavlath \& Robertson (1999), Amaral et al. (2019), Fontes (2020), entre outros autores.

Nos recentes tempos de severas pandemias e protocolos de confinamento, os argumentos positivos sobre as perspectivas florestais e madeireiras deverão ser revigorados. Mesmo nessa crise com graves consequências do COVID-19 na economia global, existem crescentes expectativas para a recuperação econômica. De acordo com Santi (2020), a cadeia florestal-madeireira se beneficiará dos novos hábitos e protocolos de higiene da sociedade criados pelas autoridades, cujas implicações vão ampliar os mercados dos segmentos dos setores fabris da celulose e papel, embalagens, paletes, etc.

O setor florestal prove uma função social essencial nesse momento de confinamento total, já que as florestas estão suprindo recursos para as indústrias e áreas recreacionais para as pessoas (Confederation of European Forest Owners, 2020). Porém, a situação ainda é desafiadora aos pequenos e médios empresários dos países subdesenvolvidos e em estágio de desenvolvimento por conta de uma maior vulnerabilidade econômica causada pela pandemia (International Labour Organization, 2020). Sendo assim, recomendações para o uso das soluções baseadas em recursos florestais estão sendo consideradas para a recuperação econômica das indústrias (United Nations, 2020). Portanto, novas medidas de estímulo são imprescindíveis para essa recuperação.

O cenário sugere que as futuras ações promotoras deverão valorizar as carreiras florestais e madeireiras mediante a regulação de suas carreiras, incentivos à silvicultura, promoção dos produtos florestais e seus benefícios e usos múltiplos e, especialmente, fortalecimento da integração da tríade Universidade-Indústria-Sociedade.

\section{Considerações Finais}

As profundas consultas em websites de universidades e literaturas científicas permitiu constatar que a Educação Florestal teve sua gênese formal em meados do Século XVIII, especificamente, na Alemanha e se espalhou globalmente a partir dos territórios vizinhos, nomeadamente, Áustria, Hungria e Rússia. O Brasil veio receber a sua primeira disciplina florestal em um curso de Agronomia somente no período final do Século XIX, sendo que a formação específica se materializou somente dois séculos depois de sua formalização alemã.

Tanto no Brasil quanto no mundo, há avanços notáveis nas Ciências Florestais constatados por Santos (2006). Esse progresso se justificou pela evolução do setor florestal, que ganhou ares de renovação mediante a implantação da Educação em Madeira e seus cursos derivados. Influenciada pelo avanço da industrialização, a Educação em Madeira se deriva da Educação Florestal como uma alternativa especializada na coleta, processamento e beneficiamento dos recursos em produtos florestais.

A Educação em Madeira foi estabelecida na América do Norte ao final do Século XIX e se formalizou na Europa no princípio secular subsequente, tendo o seu apogeu ao final desse período. Graças aos baixos níveis de industrialização, os continentes africano e latino-americano se tornaram as últimas regiões a receber as formações em madeira, o que ocorreu em meados do Século XX. Apesar de suas posições fabris representativas no contexto sul-americano, o Brasil e a Argentina vieram a oferecer o curso de Engenharia Industrial Madeireira somente nos anos finais do Século XX.

A criação de um moderno curso voltado para os tópicos específicos de processamento e tecnologia da madeira pode figurar como um fato negativo devido à redução das competências dos Engenheiros Florestais no que diz respeito à madeira. Porém, a experiência relacionada à madeira compartilhada pelos cursos modernos da Educação em Madeira contribuiu para as bases e habilidades acadêmicas desses novos profissionais. Esse fato possibilitou maiores experiências sobre a madeira e sua indústrialização, cujo conhecimento era tratado, de modo superficial e pontual, pelos cursos de graduação florestais.

A manufatura sustentável e o processamento mais eficiente são objetivos mais essenciais da Educação em Madeira, 
cuja condição contemporânea tem contribuído para um maior progresso dos setores industriais do ramo florestal. Esse caminho permitiu níveis mais elevados de racionalização de materiais, industrialização de produtos manufaturados e (re)utilização de resíduos. Essas habilidades serão vantagens e justificativas centrais para as indústrias mais limpas do futuro próximo, sendo estritamente essenciais para o desenvolvimento saudável da sociedade. Como previsão, o declínio atual nos interesses pela Educação Florestal e Educação em Madeira será revertido pela crescente procura por soluções sustentáveis e verdes, como os bioprodutos, os quais serão obtidos por cadeias fabris modernas (re)projetadas conforme as diretrizes da bioeconomia.

\section{Referências}

Acevedo-Correa, Y., Valencia-Arias, A., Bran-Piedrahita, L., Gómez-Molina, S., \& Arias-Arciniegas, C. (2019). Alternativas para modelos de gestión del conocimiento en Instituciones de Educación Superior. Ingeniare. Revista Chilena de Ingeniería, 27(3), 410-420.

Alvarado, C. A. (1998). En busca de las tres "C" en la Escuela Nacional de Ciencias Forestales (Esnacifor). Ceiba, 39(1), $123-125$.

Amaral, M. A., Borschiver, S., \& Morgado, C. R. V. (2019). Análise do segmento de bioplásticos: prospecção tecnológica em 'plásticos verdes‘, PHA e PLA. Engevista, 21(2), 228-241.

Arkhangelsk State Technical University. (2021). Faculty. https://narfu.ru/agtu/www.agtu.ru/faculty/2a1977595ffcb17974e208b0b764368amtw.html

Armstrong, J. P., Bustos, C., \& Barnes, H. M. (2014). Education in wood science and technology: an update. Wood and Fiber Science, $46(1), 3-14$.

Bachelard, E. P. (1994). Changes to forestry education. Commonwealth Forestry Review, 73(2), 94-96.

Bantel, C. A. (2007). Evolução das atribuições profissionais do engenheiro florestal. www.sbs.org.br/destaques_evolucaodasatribuicoes.doc

Barnes, H. M. (2007). Historical assessment of wood science \& technology education in North America. IUFRO All Division 5 Conference.

Barros, A. S. X. (2015). Expansão da educação superior no Brasil: limites e possibilidades. Educação e Sociedade, 36(131), 361-390.

Beijing Forestry University. (2015a). Undergraduates. http://international.bjfu.edu.cn/eng_index/about/overview/252845.html

Beijing Forestry University. (2015b). The school of material science \& technology. http://international.bjfu.edu.cn/eng_index/academics/schools/262478.html

Beijing Forestry University. (2015c). The School of Forestry. http://international.bjfu.edu.cn/eng_index/academics/schools/262454.html

Benoit, Y., \& Paradis, T. (2008). Construction de maisons à ossature bois. Saint-Germain, França: Eyrolles.

Bermuda College. (2021). Diploma in wood technology. https://www.college.bm/index.php/academics/diploma-programmes/dip-wood-technology

Bern University of Applied Sciences. (2021). Bachelor of science - wood technology. www.bfh.ch/en/studies/bachelor/wood-technology/

Berrios, M. A. (1996). D.J.577. Santiago, UTEM. http://transparencia.utem.cl/wp-content/uploads/2012/11/Res_5634.pdf

Capdeville, G. (1991). O ensino superior agrícola no Brasil. Revista Brasileira de Estudos Pedagógicos, 72(172), 229 -261.

Coleção de Leis do Império do Brasil. (1875). Decreto nº 5.957, de 23 de junho de 1875.

Confederation of European Forest Owners. (2020). Understanding COVID-19 impact on the forest. www.cepf-eu.org/news/understanding-covid-19-impactforest-sector

Consejo Nacional de Rectores. (1987). Estudio sobre la incorporación de los ingenieros en maderas y de los ingenieros metalúrgicos al Colegio Federado de Químicos y de Ingenieros Químicos. Conare: San José. 1-57.

Cummings, W. H. (1966). Education in wood science and technology. Forest Science, 12(1), 48-48.

De Araujo, V. A., Cortez-Barbosa, J., Gava, M., Garcia, J. N., Souza, A. J. D., Savi, A. F., Morales, E. A. M., Molina, J. C., Vasconcelos, J. S., Christoforo, A.L., \& Lahr, F. A. R. (2016a). Classification of wooden housing building systems. BioResources, 11(3), 7889-7901.

De Araujo, V. A., Garcia, J. N., Cortez-Barbosa, J., Gava, M., Savi, A. F., Morales, E. A. M., Lahr, F. A. R., Vasconcelos, J. S., \& Christoforo A. L. (2017). Importância da madeira de florestas plantadas para a indústria de manufaturados. Pesquisa Florestal Brasileira, 37(90), 157-168.

De Araujo, V., Polanco, C., Morales, E., Cortez-Barbosa, J., Gava, M., \& Garcia, J. (2019). Profile of professionals of the Brazilian production sector of timber housing. Journal of the Korean Wood Science and Technology, 47(5), 607-616.

De Araujo, V. A., Vasconcelos, J. S., Cortez-Barbosa, J., Morales, E. A. M., Gava, M., Savi, A. F., \& Garcia, J. N. (2016b). Wooden residential buildings - a sustainable approach. Bulletin of the Transilvania University of Brasov Series II: Forestry • Wood Industry • Agricultural Food Engineering, 9(58), 53-62.

DeSteiguer, J. E., \& Merrifield, R. G. (1979). The impact of the environmental era on forestry education in North America. 9th FAO Advisory Committee on Forestry Education. FAO-UN/PSU.

Duncan D. P., Skok, R. A., \& Richards, D. P. (1989). Forestry education and the profession's future. Journal of Forestry, 87(9), 31 -37. 
Durso, S., \& Cunha, J. V. A. (2018). Determinant factors for undergraduate student's dropout in an accounting studies department of a Brazilian public university. Educação em Revista, (34), 1-28.

École Catholique D'arts et Métiers de Lyon. (2013). Ingénieur Bois. www.ecam.fr/blog/ingenieur-bois-nouvelle-formation-de-specialite-bois-en-alternance/

École Superieure du Bois. (2019). Inventer un monde durable. www.esb-campus.fr/

Ehime University. (2019). Faculties and field of study. http://rendai.agr.ehime-u.ac.jp/english/kenkyu/

Eisenhauer, G. (1982). Comparación y análisis de la formación forestal superior en diferentes países de la America Latina. 1st Simpósio sobre Educação em Engenharia Florestal na América Latina. UFPR.

Escola Superior de Tecnologia e Gestão de Viseu. (2019). Tecnologia e Design de Mobiliário. http://www.estgv.ipv.pt/estgv/?v=304

Ettammal, S. (2020). Present status and challenges of wood science and technology education in India. International Journal of Engineering Applied Sciences and Technology, 5(4), 592-600.

Fachhochschule Salzburg. (2019). Description. https://www.fh-salzburg.ac.at/en/study/engineering/forest-products-technology-timber-constructions-bachelor/

Fernow, B. E. (1907). A brief history of forestry in Europe, the United States and other countries. New Haven: Arkose Press. p.1-682.

Fontes, S. (2020). Suzano avança em bioeconomia e quer substituir o plástico. Valor, (July 28), B4.

Food and Agriculture Organization of the United Nations. (2020). Forest sector workforce in the UNECE region Overview of the social and economic trends with impact on the forest sector. Genebra: FAO/UN. https://unece.org/DAM/timber/publications/2020/DP-76.pdf

Food and Agriculture Organization of the United Nations. (2000). State of forestry in the United States. Twentieth session. Saint Andrews: FAO/UN. www.fao.org/3/x4995e/x4995e.htm

Food and Agriculture Organization of the United Nations. (2001). Forestry curriculum development and revision. www.fao.org/3/Y1842E/y184 2e00.htm\#TopOfPage

ForestryUSA. (2019). Universities and colleges. www.forestryusa.com/universities-colleges.html

Gadjah Mada University. (2019). History. https://teknologihutan.fkt.ugm.ac.id/en/

Gardner, D. J., Kurjatko, S., Kúdela, J., \& Paule, L. (2005). The status of wood science education program. Wood and Fiber Science, 37(2), 189-191.

Hacettepe Üniversitesi. (2021). Ağaç işleri endüstri mühendisliği bölümü. http://www.aem.hacettepe.edu.tr/

Innes, J. L., \& Ward, D. M. (2007). Training at professional and technical levels. In: Commonwealth forests: an overview of the Commonwealth's forest resources. Craven Arms: CFA.

Institut Pertanian Bogor University. (2019). Forest products. https://www.ipb.ac.id/page/thh

Institute of Technology Sligo. (2019). Bachelor of science advanced wood \& sustainable building technology. itsligo.ie/courses/bsc-advanced-wood-andsustainable-building-technology/

International Educational Specialists. (2021). Forestry studies courses abroad. https://www.idp.com/global/search/forestry-studies/

International Labour Organization. (2020). COVID-19 crisis and the informal economy. Genebra: ILO.

Jolley, H. E. (2006). Biltmore forest school. https://www.ncpedia.org/biltmore-forest-school

Kangwon National University. (2021). Department history. https://paper.kangwon.ac.kr/paper/intro/history.do

Kanowski, P. J. (2008). Centennial challenges: professional forestry education in Canada and the USA in 2007, and learnings for Australia. Forest \& wood products Australia, Melbourne, Australia.

Karelia University of Applied Sciences. (2019). Bachelor's degree programmes taught in Finnish. www.karelia.fi/en/education/bachelor-s-degrees/degreeprogrammes-in-finnish

Kasetsart University. (2010). Undergraduate programs. http://www.forest.ku.ac.th/edu/tropical/index.php

Kürsten, E. (2004). Master- and PhD-programs "Wood Biology and Technology" at the University of Göttingen. 1st International Symposium Wood Science Education and Research Programmes. Arbora Publishers.

Kwame Nkrumah University of Science \& Technology. (2018). BSc courses. https://frnr.knust.edu.gh/programmes/bsc-courses

Kyoto University. (2021). Department of forest and biomaterials science. http://www. kais.kyoto-u.ac.jp/english/undergraduate/dep_forest/

Kyungpook National University. (2019). Major in wood \& paper science. wood.knu.ac.kr/

Kyushu University. (2019). Organization. https://www.agr.kyushu-u.ac.jp/english/about/

Ladeira, H.P.(2002). Quatro décadas de engenharia florestal no Brasil. SIF. 
Laney College. (2021). Wood technology. https://laney.edu/woodtechnology/

Langenbach, R. (2008). Building tall with timber: a Paean to wood construction. Structural Engineering International, 18(2), 130-132.

Linnéuniversitetet. (2021). Skog och träteknik, högskoleingenjör. https://lnu.se/program/skog-och-trateknik-hogskoleingenjor/

Macedo, J. H. P., \& Machado, S. A. (2003). A engenharia florestal da Universidade Federal do Paraná: história e evolução da primeira do Brasil. Curitiba: Editora UFPR.

McDaniel, M., Sprout, E., Bourdreau, D., \& Turgeon, A. (2012). North America: Resources. Washington, National Geographic Society. www.nationalgeographic.org/encyclopedia/north-america-resources/

Mendel University. (2019). About. https://www.ldf.mendelu.cz/en/

Ministério da Educação. (2021). Cadastro nacional de cursos e instituções de educação superior - e-MEC. http://emec.mec.gov.br/emec/nova\#avancada

Muğla Sitkı Koçman University. (2019). Department of Woodworking Industrial Engineering. http://agacisleri.mu.edu.tr/en

Mundo Vestibular. (2009). UFPR divulga a relação de candidatos por vaga. https://www.mundovestibular.com.br/vestibular/noticias/ufpr-divulga-a-relacaocandidatos-por-vaga

Murphy, P. J., \& Roberts, R. W. (1988). Forestry education in China. The Forestry Chronicle, 469-474.

Nanjing Forestry University. (2021). Undergraduates. https://eng.njfu.edu.cn/Admissions/Undergraduate/index.html

National Pingtung University of Science and Technology. (2020). Department of Wood Science and Design (Bachelor Degree). www.studyintaiwan.org/university/program/876

Natterer, J., Volz, M., \& Herzog, T. (2004). Timber construction manual. Munique: Birkhauser.

Paillé, G. G. (2003). The importance of forestry and forest engineering: past - present - future. The Forestry Chronicle, 79(5), 876-882.

Pavlath, A.E., \& Robertson, G.H. (1999). Biodegradable polymers vs. recycling: what are the possibilities? Critical Reviews in Analytical Chemistry, 29(3), $231-241$.

Pereira, A.C. (2020). O Brasil no ranking das universidades. O Estado de São Paulo, 141(46345), A3-3.

Pereira, E. F., Bernardo, M. P. S. L., D’Almeida, V., \& Louzada, F. M. (2011). Sono, trabalho e estudo: duração do sono em estudantes trabalhadores e não trabalhadores. Cadernos de Saúde Pública, 27(5), 975-984.

Poggiani, F. (1980). O curso de engenharia florestal e as perspectivas profissionais. Circular Técnica IPEF, 99, 1-7.

Poznań University of Life Sciences. (2017). Faculty of Wood Technology. https://skylark.up.poznan.pl/en/faculty-wood-technology-0

Rosenheim University of Applied Sciences. (2013). Faculty of wood and technology and construction. www.th-rosenheim.de/en/rosenheim-university-ofapplied-sciences/faculties-institutes/ faculty-of-wood-technology-and-construction/

Sands, R. (2003). Professional forestry education in Australasia - looking from the past to the future. New Zealand Journal of Forestry, $20-27$.

Santi, T. (2020). Os impactos da COVID-10 nos setores de tissue e embalagem. O Papel, 81(7), 28-30.

Seixas, F. (1989). Engenheiro florestal: que professional estamos formando? Documentos Florestais, (6), 1-11.

Santos, A.F. (2006). Caracterização do ensino da engenharia florestal no Brasil. Revista Educação Agrícola Superior, 21(1), 38-41.

Saviani, D. (2010). A expansão do ensino superior no Brasil: mudanças e continuidades. Poíesis Pedagógica, 8(2), 4-17.

Searle, S., \& Bryant, C. (2009). Why students choose to study for a forestry degree and implications for the forestry profession. Australian Forestry, 72(2), 7179.

Shizuoka University. (2019). Faculty and research guide. http://www.agr.shizuoka.ac.jp/lab/index_en.html\#br

Silva, M. L., Oliveira, S. C., Santos, M. M., \& Scalco, A. R. (2020). Uma análise da evasão discente em cursos de Engenharia de uma Universidade Pública Brasileira. Research, Society and Development, 9(8), e70985159, 1-24.

Simões, B. S., \& Custódio, J. F. (2020). A evasão em uma Licenciatura em Física: Um olhar para as relações com o saber. Research, Society and Development, 9(5), e59953207, 1-30.

Smith, I., \& Frangi, A. (2008). Overview of design issues for tall timber buildings. Structural Engineering International, $18(2), 141-147$.

Spinelli, R., Visser, R., \& Han, H.-S. (2019). A decade of Forest Engineering: achievements and future directions. Forests, 10(724), 1-12.

State University of New York. (2019). A history of ESF. www.esf.edu/welcome/history.htm

Stellenbosch University. (2019). Department of Forest and Wood Science. https://www.sun.ac.za/english/faculty/agri/forestry

Straka, T. J., \& Childers, C. J. (2006). Consulting foresters' view of professional forestry education. Natural Sciences Education, 35(1), 48-52. 
Sunyani Technical University. (2019). Department of Wood Technology. https://stu.edu.gh/dpts/fbeaa-wt/

Swedish University of Agricultural Sciences. (2020). About us. https:/www.slu.se/en/departments/forest-biomaterials-technology/om-oss/om-oss/

Technical University in Zvolen. (2017). Faculty of Wood Sciences and Technology. https://df.tuzvo.sk/en

Technische Universität Graz. (2019). Education. https://www.tugraz.at/en/institutes/lignum/teaching/general/

Technische Universität München. (2021). Wood Research Munich. https://www.hfm.tum.de/en/start/

Tecnológico de Costa Rica. (2021). Escuela de Ingeniería Forestal. https://www.tec.ac.cr/escuelas/escuela-ingenieria-forestal

Temu, A.B., Okali, D., \& Bishaw, B. (2006). Forestry education, training and professional development in Africa. International Forestry Review, 8(1), 118125 .

Testa, B. M.,\& Gupta, R. (2004). Ivory towers - the status of wood design education in American universities. Engineered Wood Journal, (Spring), 20-22.

Transilvania University of Brasov. (2019). Faculty of Wood Engineering. http://old.unitbv.ro/ilen/FirstPage/AboutFaculty.aspx

Ukrainian National Forestry University. (2019). Forestry Institute Lviv. http://www.nltu.edu.ua/index.php/home/istoriia-stanovlennia/item/21-lvivskyylisotekhnichnyy-instytut

United Nations. (2020). Forests: at the heart of a green recovery from the Covid-19 pandemic. Nova Iorque: UN-DESA.

Universidad Autonoma de Chapingo. (2018). web.chapingo.mx/oferta-educativa/

Universidad de Chile. (2021). Facultad: historia. http://www.forestal.uchile.cl/facultad/presentacion/73258/historia

Universidad de Chile. (2019). Mallas curriculares. http://uchile.cl/n76706

Universidad de la Sierra Juárez. (2019). Ingeniería en tecnología de la madera. http://www.unsij.edu.mx/ing_madera.html

Universidad de Misiones. (2017). Ingeniería en industrias de la madera. www.facfor.unam.edu.ar/carreras/ingenieria-en-industria-de-la-madera/

Universidad de San Carlos de Guatemala. (2019). Cunzac. https://cunzac.usac.edu.gt/index.php/ingenieria-en-industrias-agropecuarias-y-forestales/

Universidad del BíoBío. (2019). História. https://ubiobio.cl/admision/Historia/

Universidad Distrital Francisco José de Caldas. (2021). Ingeniería Forestal. http://www1.udistrital.edu.co:8080/web/ingforestal

Universidad Michoacana de San Nicholas de Hidalgo. (2019). Facultad de Ingeniería en Tecnología de la Madera. www.fitecma.umich.mx/

Universidad Nacional Agraria La Molina. (2011). Historia. http://www.lamolina.edu.pe/facultad/forestales/web2007/Presentacion/Presentacion.php

Universidad Nacional de Ciencias Forestales. (2018). Ingeniería en industrias y negocios de la madera. unacifor.edu.hn/?page_id=1803

Universidad Nacional de Misiones. (2017). Historia, Misión y Visión. https://www.facfor.unam.edu.ar/la-facultad/mision-vision/

Universidad Nacional de Santiago del Estero. (2017). Ingeniería en Industrias Forestales. https://fcf.unse.edu.ar/index.php/courses/ingenieria-en-industriasforestales/

Universidad Nacional Experimental de Guayana. (2009). Ingeniería en indústrias $\quad$ forestales. http://www.uneg.edu.ve/academia/htmls/?p=academia/pregrado/carreras/forestal.html

Universidad Privada de Santa Cruz de la Sierra. (2017). Acerca de la facultad. www.upsa.edu.bo/es/acerca-de-la-facultad-de-ingenieria

Universidad Tecnológica de Pereira. (2016). Ingeniería en Procesos Sostenibles de las Maderas. www.utp.edu.co/registro/pregrado/400/ingenieria-enprocesos-sostenibles-de-las-maderas-ofrecido-semestralmente? $\mathrm{v}=2$

Universidad Tecnológica Equinoccial. (2019). UTE Repositorio digital. http://repositorio.ute.edu.ec/handle/123456789/108

Universidade Estadual Paulista. (2021). Proposta de alteração do projeto político-pedagógico do curso de graduação em Engenharia Industrial Madeireira. www.itapeva.unesp.br/\#!/ensino/graduacao/cursos/engenharia-industrial-madeireira/projeto-pedagogico/

Universidade Federal do Espírito Santo. (2013). Engenharia Florestal e Engenharia Industrial Madeireira. florestaemadeira.ufes.br/apresentacao-0

Universidade Federal do Paraná. (2015). Nucleo de concursos UFPR. http://www.nc.ufpr.br/concursos_institucionais/uf pr/ps2016/candvaga_curso.htm

Universidade Federal do Paraná. (2008). Projeto pedagógico do curso de Engenharia Industrial Madeireira. www.madeira.ufpr.br/coordenacao/Projeto\%20Pedag\%C3\%B3gico2008\%20CEIMUFPR.pdf

Universidade Federal de Pelotas. (2019). Engenharia Industrial Madeireira. 2019. https://wp.ufpel.edu.br/ceimad/?page_id=2

Universität für Bodenkultur $\quad$ Wien. $\quad$ (2019).

https://boku.ac.at/universitaetsleitung/rektorat/stabsstellen/oeffentlichkeitsarbeit/themen/geschichte/geschichte/zweite-republik

Universität Hamburg. (2018). Wood Science. https://www.biologie.uni-hamburg.de/en/einrichtungen/ihw.html 
Research, Society and Development, v. 10, n. 7, e3010716084, 2021

(CC BY 4.0) | ISSN 2525-3409 | DOI: http://dx.doi.org/10.33448/rsd-v10i7.16084

Université de Lorraine. (2019). https://formations.univ-lorraine.fr/fr/diplome-d-ingenieur/1899-ingenieur-enstib-ecole-nationale-superieure-des-technologieset-industries-du-bois.html

Universiti Sains Malaysia. (2017). Bioresource, Paper and Coatings Technology. https://indtech.usm.my/index.php/admission/undergraduate/bioresourcepaper-and-coatings-technology

University of Education - Winneba. (2019). Construction and wood technology education. https://www.uew.edu.gh/departments/construction-and-woodtechnology-education

University of Forestry. (2019). History. https://tu.bg/en/university/presentation-of-the-university/history

University of Ljubljana. (2021). Milestones. https://www.bf.uni-lj.si/en/organisation/wood-science-and-technology/

University of Nigeria. (2020). Agricultural \& Bioresources Engineering - Course Modules. https://engineering.unn.edu.ng/agric-bioresources-engineeringprogrammes-2/

University of Sopron. (2013). Faculty of Wood Sciences. http://www.uniwest.hu/index.php/2370/?\&L=4

University of Tokyo. (2019). Department of biomaterial sciences. www.a.u-tokyo.ac.jp/english/departments_e/d-bs.html

University of Zabol. (2019). Faculty of natural resources. http://www.uoz.ac.ir/HomePage.aspx?TabID=7673\&Site=nr\&Lang=en-US

van de Kuilen, J. W., Ceccotti, A., Xia, Z., He, M., \& Li, S. (2010). Wood concrete skyscrapers. 2010 World Conference on Timber Engineering.

Vietnam National University of Forestry. (2017). University. http://env.vnuf.edu.vn/university

Visser, R. (2007). What can forest engineering do for forestry in New Zealand? New Zealand Journal of Forestry, 52(August), 4-5.

Widzial Technologii Drewna. (2019). Historia. http://wtd.sggw.pl/Content/historia 